\title{
Quantifying the impact of the structural uncertainty on the gross rock volume in the Lubina and Montanazo oil fields (Western Mediterranean)
}

\author{
Carla Patricia Bárbara ${ }^{1}$, Patricia Cabello ${ }^{2,3}$, Alexandre Bouche ${ }^{4}$, Ingrid Aarnes ${ }^{5}$, Carlos Gordillo ${ }^{6}$, Oriol Ferrer ${ }^{2,3}$, \\ Maria Roma ${ }^{2,3}$, and Pau Arbués ${ }^{2,3}$ \\ ${ }^{1}$ independent researcher: Nottingham, UK \\ ${ }^{2}$ Dept. Dinàmica de la Terra i de l'Oceà, Facultat de Ciències de la Terra, Universitat de Barcelona, \\ c/Martí i Franquès s/n, 08028, Barcelona, Spain \\ ${ }^{3}$ Geomodels Research Institute, Universitat de Barcelona, Spain \\ ${ }^{4}$ Emerson Automation Solutions, Lysaker Torg 45, 1366, Lysaker, Norway \\ ${ }^{5}$ Norwegian Computing Center, Gaustadalleen 32a, 0373 Oslo, Norway \\ ${ }^{6}$ Repsol, Repsol Campus Madrid, Blue Building, c/Méndez Álvaro 44, 1st floor, 28045, Madrid, Spain
}

Correspondence: Patricia Cabello (pcabello@ub.edu)

Received: 26 March 2019 - Discussion started: 2 April 2019

Revised: 26 July 2019 - Accepted: 19 August 2019 - Published: 27 September 2019

\begin{abstract}
Structural uncertainty is a key parameter affecting the accuracy of the information contained in static and dynamic reservoir models. However, quantifying and assessing its real impact on reservoir property distribution, in-place volume estimates and dynamic simulation has always been a challenge. Due to the limitation of the existing workflows and time constraints, the exploration of all potential geological configurations matching the interpreted data has been limited to a small number of scenarios, making the future field development decisions uncertain.

We present a case study in the Lubina and Montanazo mature oil fields (Western Mediterranean) in which the structural uncertainty in the seismic interpretation of faults and horizons has been captured using modern reservoir modeling workflows. We model the fault and horizon uncertainty by means of two workflows: the manually interpreted and the constant uncertainty cases. In the manually interpreted case, the zones of ambiguity in the position of horizons and faults are defined as locally varying envelopes around the best interpretation, whose dimensions mainly vary according to the frequency content of the seismic data, lateral variations of amplitudes along reflectors, and how the reflectors terminate around faults when fault reflections are not present in the seismic image. In the constant case, the envelope dimensions are kept constant for each horizon and each fault.
\end{abstract}

Both faults and horizons are simulated within their respective uncertainty envelopes as provided to the user. In all simulations, conditioning to available well data is ensured. Stochastic simulation was used to obtain 200 realizations for each uncertainty modeling workflow. The realizations were compared in terms of gross rock volumes above the oil-water contact considering three scenarios at the depths of the contact.

The results show that capturing the structural uncertainty in the picking of horizons and faults in seismic data has a relevant impact on the volume estimation. The models predict percentage differences in the mean gross rock volume with respect to best-estimate interpretation up to $7 \%$ higher and $12 \%$ lower (P10 and P90). The manually interpreted uncertainty workflow reports narrower gross rock volume predictions and more consistent results from the simulated structural models than the constant case. This work has also revealed that, for the Lubina and Montanazo fields, the fault uncertainty associated with the major faults that bound the reservoir laterally strongly affects the gross rock volume predicted. The multiple realizations obtained are geologically consistent with the available data, and their differences in geometry and dimensions of the reservoir allow us to improve the understanding of the reservoir structure. 
The uncertainty modeling workflows applied are easy to design and allow us to update the models when required. This work demonstrates that knowledge of the data and the sources of uncertainty is important to set up the workflows correctly. Further studies can combine other sources of uncertainty in the modeling process to improve the risk assessment.

\section{Introduction}

Geological modeling is a powerful tool that allows us to obtain realistic representations of the subsurface, which in turn gives a better understanding of the most geologically complex scenarios (e.g., Jolie et al., 2015; Hoffman et al., 2008; Latief et al., 2012). Geological modeling has also become a key task used for the correct management of georesources, such as hydrocarbons, mineral and geothermal resources, and water management, where it is used to make decisions and to perform risk assessments. Geological modeling is also applied in public works and civil engineering.

Models describing the structure of the subsurface are built from the best-estimate interpretation of data. Due to software limitations and time constraints, only a limited number of possible modeling scenarios are produced by the interpreters. This practice, which ignores the other equally probable solutions that match all the available data and interpretations, has often led to unpleasant surprises, for example, when new wells have been drilled. Another challenge is that many of these models are not easy to update with new data when they become available (Seiler et al., 2009; Skjervheim et al., 2012; Pettan and Strømsvik, 2013), and companies may run the risk of taking decisions based on models that are no longer valid.

A geological model of the subsurface should capture the key uncertainties relevant for the modeling task in question. Most modeling workflows to a large degree acknowledge the uncertainty associated with the input data when it comes to populating the 3-D reservoir grids with static and dynamic properties (e.g., Cabello et al., 2011, 2018). However, many of these workflows operate with a locked geometry of the 3-D grid and thus are not able to capture the often highly significant structural uncertainties. The aim of incorporating all significant uncertainties is to improve the predictive power of the models.

In particular, the uncertainty related to the geological structure of the subsurface is considered to produce a large impact on outcomes obtained from the geological model. The structural uncertainties are relevant for the most common reservoir modeling aims, such as static volume estimates, dynamic flow simulations, and well planning and drilling operations. The structural uncertainty is affected by the quality, resolution and spatial distribution of the input data (Wellmann and Regenauer-Lieb, 2012; Bond, 2015). These uncertainties should be propagated through each step in the subse- quent modeling workflow (MacDonald et al., 2009; Suslick et al., 2009; Neumann et al., 2012). Such workflows needs to be fully automated in order to provide rapid and efficient results.

Various sources of structural uncertainty exist, including conceptual, geophysical and well data uncertainties. Conceptual uncertainty responds to the inherent uncertainty in the interpretation of data that mainly comes from human bias and depends on the expertise of the interpreter (Bond et al., 2007; Rojas et al., 2010; Bond, 2015; Alcalde et al., 2017a, b; Howley and Meyer, 2015). It explains differences in interpretations by different geoscientists that result from the same input data.

Geophysical uncertainties associated with seismic data affecting a structural model are those resulting from migration, time picking (interpretation) and time-to-depth conversion (Thore et al., 2002). The uncertainty associated with the seismic interpretation of horizons and faults is inherent to the low resolution and quality of seismic data. The vertical resolution of seismic images is often below the scale of detailed stratigraphic zonation within reservoirs (Sheriff, 1992). This fact implies high uncertainty and low confidence in the position and geometry of the horizons in the structural model built based on the picking of reflectors (Leahy and Skorstad, 2013). The poor quality of seismic data near faults also generate high uncertainty in their interpretation (Thore et al., 2002; Røe et al., 2014). Generally, faults do not generate seismic reflections, and they are interpreted based on reflector terminations. Nevertheless, reflector terminations can also be produced by other geophysical and geological factors, such as noise in the seismic data, stratigraphic pinchouts, facies changes or unconformities (Alcalde et al., 2017b). Additionally, faults are typically interpreted as singular surfaces whereas they are zones of deformation (Røe et al., 2014).

The time-to-depth conversion is another major source of uncertainty in the structural model, since the true velocity model is not generally known (Thore et al., 2002; Fomel and Landa, 2014). Average velocities can be estimated from well data, but the lateral coverage is usually low. To amend this, seismic velocities can be used to set up a velocity model for depth conversion.

Uncertainty associated with wells comes from the well position, well trajectory and interpretation of well picks (markers, well tops) (Stenerud et al., 2012; Howley and Meyer, 2015; Pakyuz-Charrier et al., 2018). Particularly, capturing well uncertainty is challenging in reservoirs with multiple horizontal wells, where the adjustment of horizons to honor well information is often in conflict. This uncertainty accumulates when going down the well bore.

Up to now, different methodologies to capture the uncertainty in the geological structure have been developed, and some have been included as an integrated part of the modeling workflow. Modeling the uncertainty associated with fault shape and location has been addressed by Hollund et al. (2002), Holden et al. (2003), Røe et al. (2014), and Qu et 
al. (2015), amongst others. Manzocchi et al. (2008) evaluated the impact on the production of the uncertainty on sedimentological characteristics of shallow marine reservoirs combined with the fault uncertainty associated with fault density and permeability. Seiler et al. (2009) presented a reservoir modeling workflow that evaluates the structural uncertainty, where reservoir models use elastic grids that are deformed according to the top and the basal simulated reservoir horizons. Wellmann et al. (2010) develop a methodology for modeling the uncertainty in the geological structure of the subsurface related to the error, bias or imprecision in input data. Neumann et al. (2012) present a case study in which a workflow that includes a variety of uncertainty sources (e.g., time-to-depth conversion, fluid contacts and petrophysical properties) is used to estimate oil-in-place volumes. They produce multiple realizations of the depth surfaces based on Bayesian kriging and simulation using Cohiba tool (Abrahamsen, 1993); then 3-D grids for each realization are built and the rest of uncertainties are added to the model. Ramos Pinto et al. (2017) present a methodology for capturing the uncertainty related to seismic data by using seismic attributes to determine zones of high and low quality in the seismic image.

The integrated modeling workflows presented in Leahy and Skorstad (2013), Aarnes et al. (2014), and Howley and Meyer (2015) are capable of capturing uncertainties associated with any property and step of the modeling workflow. These workflows have evolved from methodologies described in MacDonald et al. (2009), Skjervheim et al. (2012) and Stenerud et al. (2012), and in turn integrate algorithms for the horizon simulation based on a Bayesian statistical approach by Abrahamsen $(1993,2005)$ and Abrahamsen and Benth (2001).

The aim of this article is to capture the structural uncertainty associated with geophysical data in a highly fractured and small reservoir and to use it to evaluate the impact on the predicted gross rock volume (GRV), i.e., the volume of the reservoir rock above the oil-water contact. Our case study corresponds to the Lower Cretaceous and Basal Tertiary Group (Oligocene-Miocene) reservoirs of the Lubina and Montanazo mature oil fields. These fields are located in the northeastern part of the Valencia Trough, offshore Catalonia in the northwestern Mediterranean Sea. The GRV is a main input in the estimation of reserves. Therefore, it is one of the most relevant parameters to evaluate in uncertainty studies, not only during the appraisal and development stages but also during the whole field life cycle of a reservoir (MacDonald et al., 2009).

We set up two different workflows to model the structural uncertainty: the manually interpreted case, from here on referred to as the manual case, and a constant uncertainty case. They differ in the accuracy with which the uncertainty around the structural interpretation of horizons and faults is captured. We generate multiple scenarios of the structural model and of the 3-D reservoir grid, with varying geometries.
Additionally, three different scenarios of the oil-water contact (OWC) depth corresponding to the proven (named low case), probable (intermediate case) and the possible cases (high case), were also considered for the GRV calculations.

This paper has been organized in three main parts. First, an introduction to the geological setting of the oil fields, followed by a description of the dataset is presented. Second, we describe the methods used to model the structural uncertainty and we document the modeling setup. Finally, we present and discuss the main results obtained.

\section{Lubina and Montanazo oil fields}

\subsection{Geological setting}

The Lubina and Montanazo oil fields are situated $60 \mathrm{~km}$ offshore northeast Iberian Peninsula, in the Mediterranean Sea (Fig. 1). The fields are located in the Valencia Trough, a subbasin that is part of the northwestern Neogene Mediterranean rift system (Roca, 1994; Maillard and Mauffret, 1999; Roca et al., 1999; Granado et al., 2016; Klimowitz et al., 2018; Roma et al., 2018). The Valencia Trough developed under an extensional tectonic regime from the Oligocene to recent times (Roca et al., 1999) and is characterized by northeastsouthwest-oriented horsts and grabens. Prior to the Neogene extension, the area was affected by a Mesozoic rift, which was followed by a period dominated by compressional processes during the Paleogene (Roca, 1994).

The main reservoirs in the Lubina and Montanazo fields are the Lower Cretaceous rocks and the Basal Tertiary Group (BTG), which are intensely fractured and affected by diagenesis (Fernandez at al., 2015; Fig. 2). The Cretaceous reservoir is made up of limestones and marls that were affected by subaerial erosion and karstification during the Paleogene uplift. The BTG is upper Oligocene-lower Miocene in age and was deposited unconformably over the Mesozoic. It is composed of breccias and conglomerates of transitional and marine environments, which resulted from weathering and the erosion of the Paleogene paleohighs, and of reefal carbonates (Rodríguez-Morillas et al., 2013). During the Miocene rifting, erosion and local karst rejuvenation of the Cretaceous carbonates and the BTG in the structural highs took place.

The Casablanca Group was deposited above the BTG in the early Miocene (Fig. 2). It is mainly composed of black marlstones, which are the main source rock in the area, and hemipelagic marly limestones and mudstones. The source rock contains kerogen type II and started to generate oil during the Pliocene. The main local seals of the Lubina and Montanazo reservoir are the mudstones and marly limestones of the Casablanca Group and the limestones and mudstones of the middle Miocene San Carlos Group. The mudstones of the upper Miocene Castellón Group are the regional seal in the area (Rodríguez-Morillas et al., 2013) (Fig. 2). 


\section{(a)}

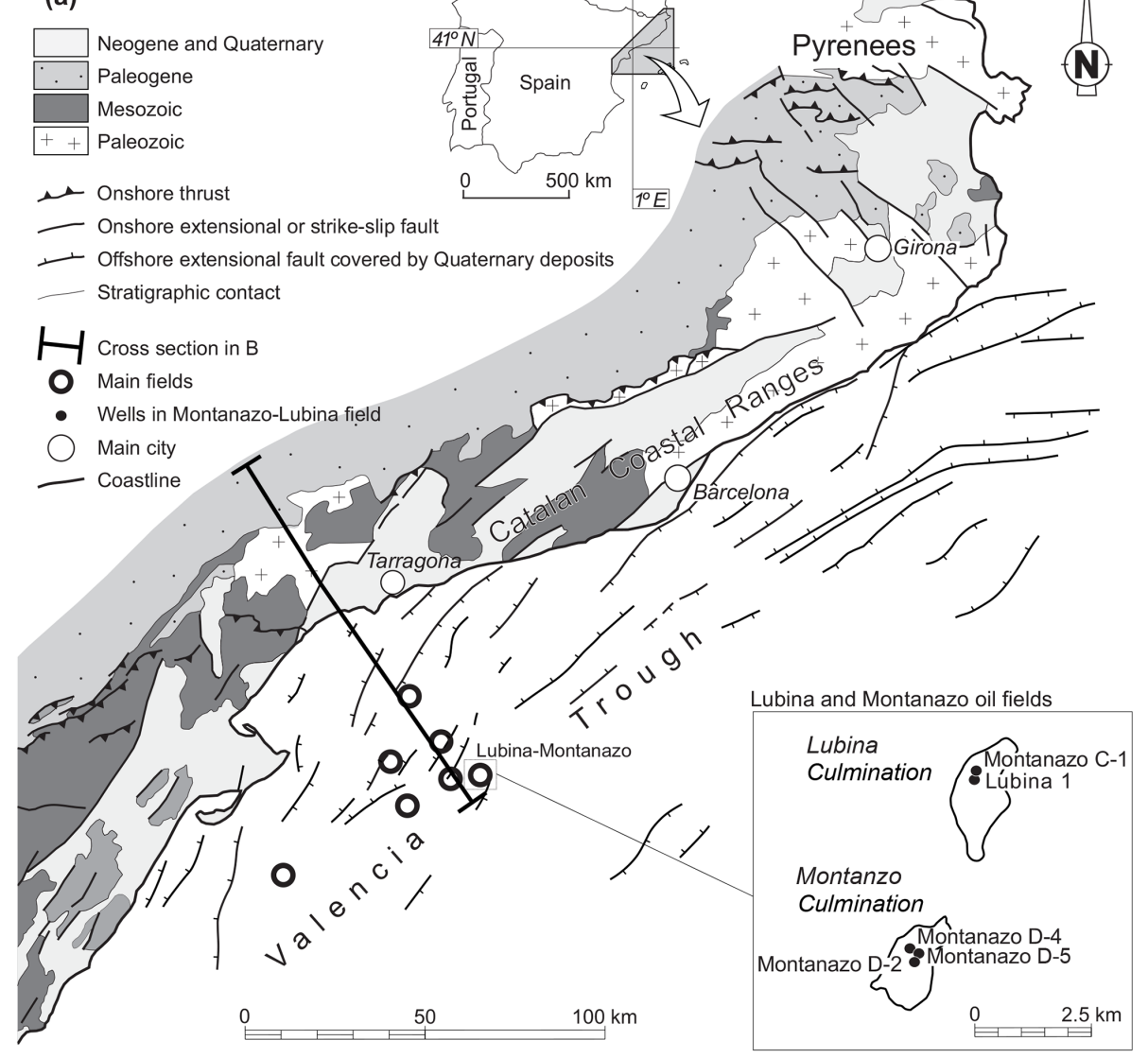

(b)

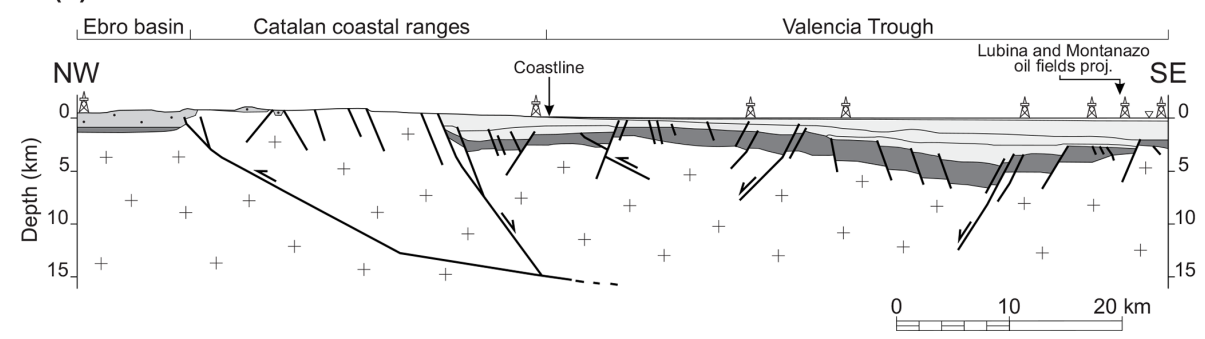

Figure 1. (a) Geological map of the northeastern part of the Iberian Peninsula showing the location of the Lubina and Montanazo oil fields. The Montanazo culmination forms the southwestern part of the field where Montanazo D-2, Montanazo D-4 and Montanazo D-5 wells were drilled. The Lubina culmination corresponds to the northeastern part and has the Montanazo C-1 and Lubina 1 wells. Modified from Roca (1994) and Roca et al. (1999). (b) Regional cross section from the Ebro basin to the Valencia Trough located a few kilometers south of Lubina and Montanazo oil fields. Modified from Cabrera et al. (2004).

The trap of Lubina and Montanazo fields consists of a SSW-NNE-trending structural paleohigh, with at least three distinct closures along strike (Fernandez et al., 2015). In detail, the paleohigh is separated into two zones: the Lubina culmination that forms the northeastern part of the structure and the Montanazo culmination, which corresponds to the southwestern part (Fig. 1a). The OWC for the Lubina and Montanazo culminations is located at different depths indi- cating that the reservoirs in both culminations are disconnected. The Montanazo and Lubina fields have been productive from the Lubina 1 and Montanazo D-5 wells, respectively, since 2009.

\subsection{Dataset}

The study area is $1.1 \mathrm{~km}$ wide and $5 \mathrm{~km}$ long, and includes both the Lubina and the Montanazo culminations. The 


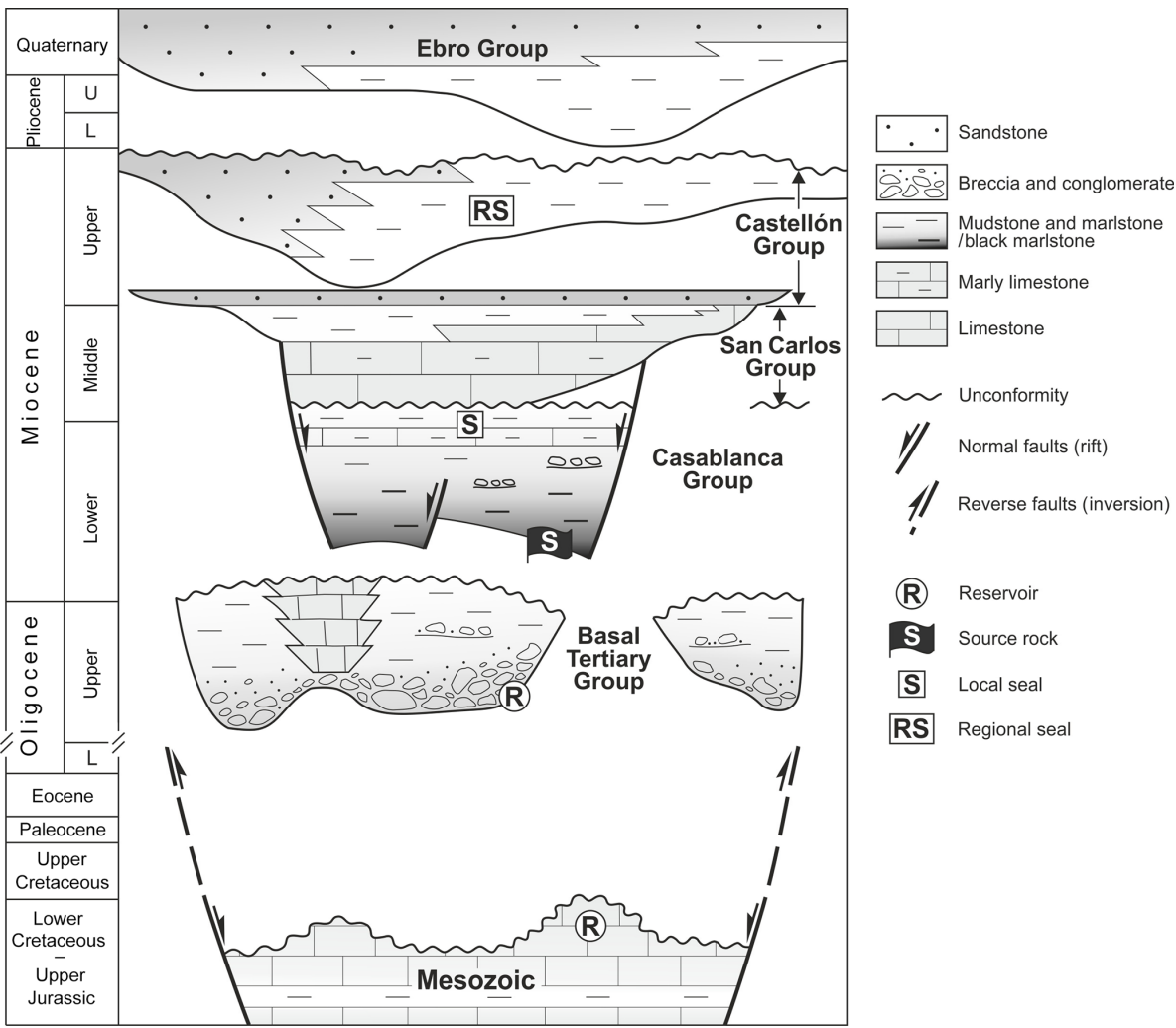

Figure 2. Chronostratigraphic diagram of the study area showing the age and main lithologies of the infill of the Valencia Trough in the Montanazo and Lubina field area. The reservoir, source and seal rocks are also indicated.

dataset was provided by Repsol and consists of the following things.

- A prestack time-migrated 3-D seismic cube, which was acquired and processed in 2006. A conventional acquisition system with a bandwidth between 8 and $80 \mathrm{~Hz}$ was used. The frequency content ranges from 20 to $40 \mathrm{~Hz}$ and the time window for the seismic picking is $20 \mathrm{~ms}$. The vertical resolution of the seismic data is $45 \mathrm{~m}$.

- A 3-D seismic interpretation of 6 stratigraphic horizons and 21 faults, which delineate the structure of the reservoir. The horizons include, from top to base, (1) the uppermost horizon (top of the model), which extends throughout the study area and is located between 80 and $200 \mathrm{~m}$ above the underlying stratigraphic horizons; (2) the top of the BTG in the Montanazo culmination; (3) the top of the upper BTG and (4) the top of the lower BTG in the Lubina culmination; (5) the top of the Cretaceous, which is an unconformity present along the study area; and (6) the basal surface (base of the model), a surface located approximately $200 \mathrm{~m}$ below the Cretaceous unconformity.

- Five wells (Lubina 1, Montanazo C-1, Montanazo D5, Montanazo D-4 and Montanazo D-2; Fig. 1a) with a sonic log available and with the position of three stratigraphic horizons, which correspond to the top of the BTG in the Montanazo culmination, the top of the lower BTG in the Lubina culmination and the top of the Cretaceous.

- An interval velocity model that was built using a 3$\mathrm{D}$ root-mean-square migration velocity field calibrated with velocities from well data, including the sonic log and a check shot survey. Interval velocities range from 1528 to $5028 \mathrm{~m} \mathrm{~s}^{-1}$.

\section{Methods for the structural uncertainty modeling}

\subsection{Manual and constant uncertainty workflows}

The sources for uncertainties considered in this work are related to the seismic interpretation of both horizons and faults. These uncertainties were captured using the structural uncertainty modeling tools in Roxar RMS ${ }^{\circledR}$, by Emerson Automation Solutions. These tools enable the design of a series of processes that are organized in an automated workflow. Thus, the models obtained can be easily revised and updated. A diagram showing the main steps in the uncertainty modeling workflow described in this work is shown in Fig. 3. 


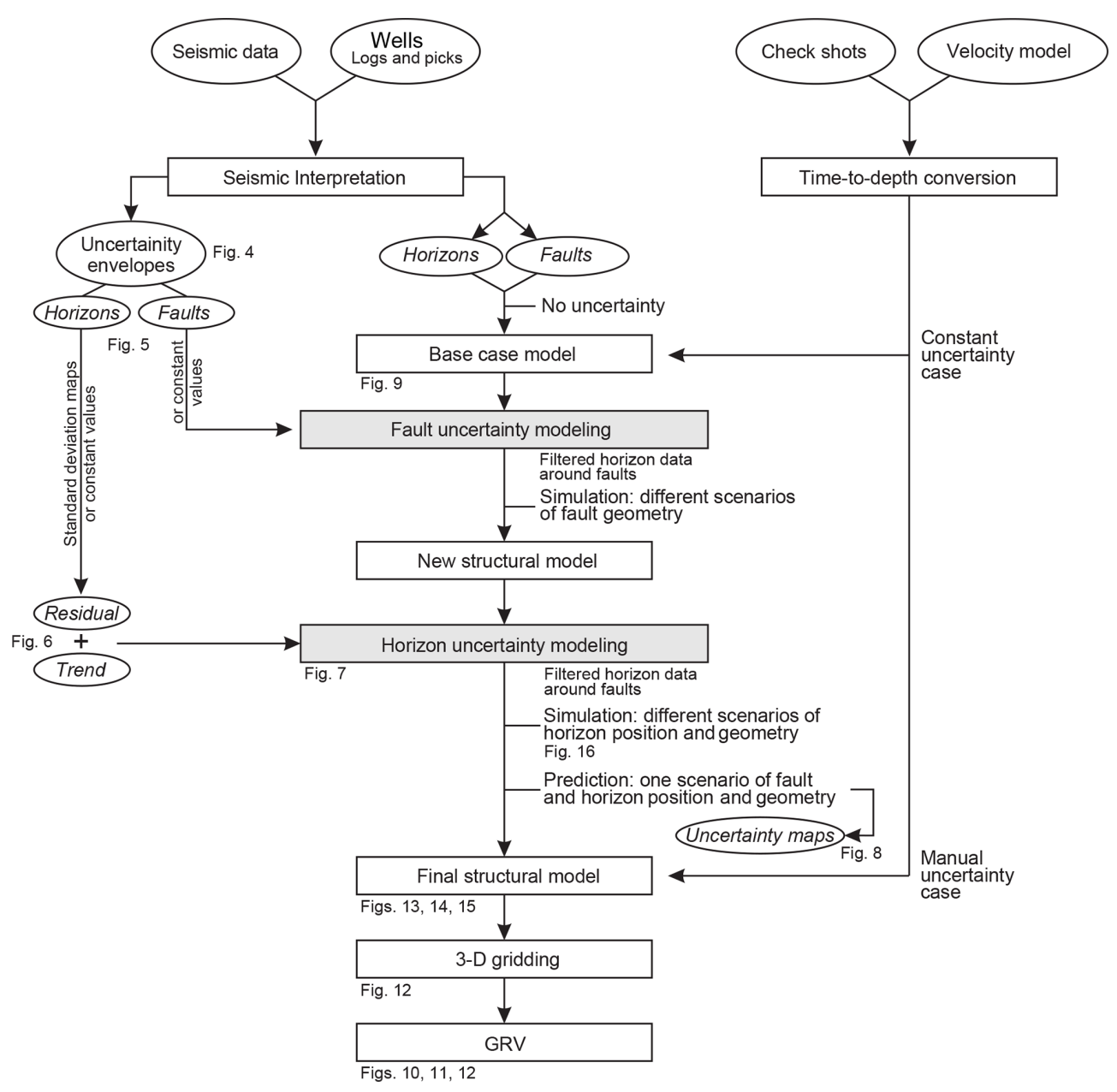

Figure 3. Diagram showing the steps of the workflow applied for both the manual and the constant uncertainty modeling cases. An initial structural model is constructed using the best-estimate interpretation of the seismic data. The fault uncertainty, first, and the horizon uncertainty, later, are added into the model to obtain a final structural model reproducing different scenarios of fault and horizon geometry and position. The scenarios are finally compared in terms of gross rock volumes (GRV) to evaluate the impact of the structural uncertainty. The numbers of figures illustrating the modeling steps are indicated.

Low-frequency content events, lateral variations of amplitudes along reflectors, diffraction areas and lack of seismic reflections of fault surfaces often represent zones of ambiguity in the position of horizons and faults. We captured these ambiguous zones by defining uncertainty envelopes around an initial horizon and fault interpretation (Fig. 4). The definition of the envelopes can be performed either manually while interpreting or automatically as a constant value across the whole surface. In the manual case, the dimensions of the uncertainty envelopes around each interpreted surface are based on a visual inspection of variations in the frequency content and in the amplitude of the seismic event, of the distance of reflector terminations around faults and of diffractions, if present. In the constant uncertainty case, the dimension of the envelope is set as a constant distance to the interpreted surface (i.e., constant distance above and below horizons and along both sides of faults), independently of the fact that the uncertainty area in picking the surface varies along the interpretation trace. A detailed understanding of the data and the acquisition and processing of the seismic image are required to properly determine the constant uncertainty value (Leahy and Skorstad, 2013).

A structural model reproducing the best-estimate interpretation is required prior to the uncertainty modeling. In this paper, this is referred to as the base case model (Fig. 3). It was initially built in the time domain using the 21 fault and 6 horizon traces interpreted in the seismic cube. Subsequently, it was converted to the depth domain applying the interval velocity model. The base case model (in the time or in the depth domain, depending on the modeling workflow) is a reference to build new structural models using the sampled perturbance distribution for faults and horizons. Perturbances record the structural uncertainty in picking the seismic events (faults and horizons). 


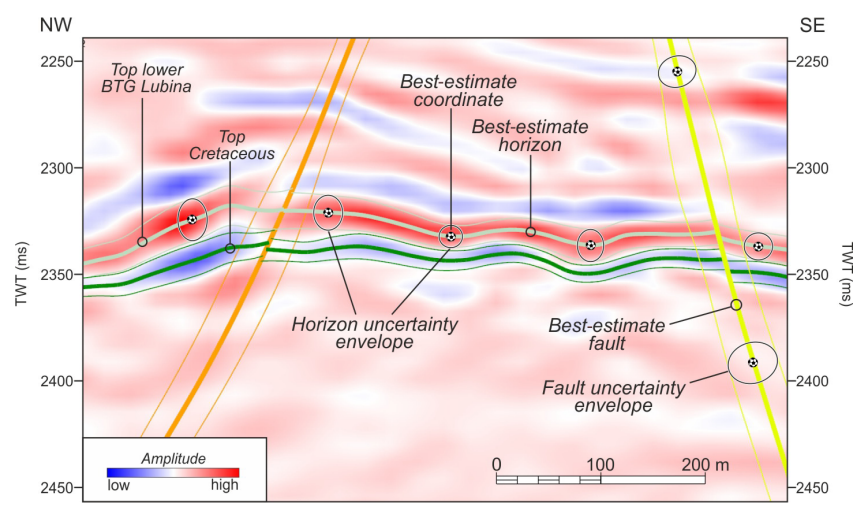

Figure 4. Best-estimate interpretation of the horizons corresponding to the top of the lower BTG in the Lubina culmination and the top of the Cretaceous and of two faults, as well as the uncertainty envelope around the best estimate. This example illustrates the manual uncertainty case; note that the envelope sizes vary along the interpretation according to the degree of ambiguity in the seismic data.

The uncertainty of faults and horizons can either be considered together or separated in the modeling process. When the fault uncertainty is added, a new structural model is created (called new structural model in Fig. 3). Subsequently, the horizon uncertainty is included and a structural model with both the fault and horizon uncertainty is finally obtained (called final structural model in Fig. 3). The structural models obtained considering the uncertainties can be combined with other steps in the reservoir modeling workflow (e.g., 3$\mathrm{D}$ gridding, property modeling, and flow simulation). The effect of structural uncertainties on the volume estimations can be highly nonlinear, and the only way to do a proper evaluation is to make stochastic simulations of the geometries. By integrating structural variations into the overall workflow, the interaction with other parameters can also be evaluated.

The data used in the modeling setup for both workflows are summarized in Fig. 5. The constant uncertainty case was built from the base case model in the depth domain, whereas the manual uncertainty workflow was based on the structural model in time (Fig. 3).

\subsection{Fault uncertainty modeling}

Simulation of the faults is the first step in the proposed workflow (Fig. 3). Different solutions or realizations of fault surfaces considering the related uncertainty are modeled using a Monte Carlo simulation (Holden et al., 2003). The simulation results in fault positions changing laterally within the interpreted envelope (Fig. 4). The size of the envelopes or displacement can differ between the hanging wall and the footwall of the faults. In addition, uncertainty in the strike, dip and throw of faults can be evaluated. For the constant uncertainty case, a specific constant envelope dimension for each fault was selected. Depending on the fault, the values applied ranged between 17.3 and $35.5 \mathrm{~m}$ (Fig. 5). In the interpreted case, this envelope was adjusted according to how the uncertainty zone (i.e., zone of ambiguity when picking the fault) varies along each interpreted fault trace. In the study dataset, faults do not produce seismic reflections nor diffractions, and their interpretation was mainly based on the distance of the reflector terminations (Fig. 4).

New truncations between faults or removed truncations originally defined in the initial structural model can occur amongst some of the structural model scenarios obtained considering the fault uncertainty, and they need to be checked. The fault changes can also affect the horizon interpretations in zones near the faults. To address this problem, the horizon data in the initial structural model were filtered out around the faults. This is a common procedure to get a realistic fault displacement across the fault plane. Finally, a new structural model with the fault realizations simulated was subsequently built using the filtered horizon data as input data (Fig. 3).

\subsection{Horizon uncertainty modeling}

In the horizon uncertainty modeling, each horizon is modeled as the sum of a trend and a residual (Figs. 6 and 7). The trend is used to reproduce the large-scale variation in the location and shape of the horizons and corresponds to the best-estimate interpretation. The residual enables us to capture small-scale or local variations between the trend and the unknown true depth of the horizon. It corresponds to differences between data and trends and allows the simulated trends to be adjusted to match the well observations. The residual is assumed to be a Gaussian random field with a mean of zero and standard deviation as specified by the user (Abrahamsen; 1999). Vertically, the residual is defined by a standard deviation value, whereas its lateral continuity is determined by a variogram.

To capture the total horizon uncertainty, the uncertainty in the trend and the residual are specified (Fig. 7c, d). The values of these uncertainties are associated with multiple factors, including the frequency content, amplitude of the seismic events and presence of diffractions, the uncertainty of the velocity model, the well density and quality of well logs, and the confidence in the interpretation of data. The trend uncertainty is used to constrain how much a trend is allowed us to shift vertically, and the residual uncertainty is used to constrain how much a surface can deviate away from the trend to adjust to the well data. The variogram for the residual will determine the shape of the noise when simulating surfaces.

The horizons can be modeled deterministically or stochastically (i.e., Monte Carlo simulation). The deterministic or predicted method represents the average results of all the simulations. In prediction mode, the trend is shifted according to a posterior trend coefficient, which is calculated from the prior uncertainty and the well observations (Abrahamsen et al., 2018) (Fig. 7e). To fit the well data, the trend is locally adjusted to the well picks by kriging within the residual 


\begin{tabular}{|c|c|c|c|c|c|c|}
\hline & & & Manual uncertainty case & \multicolumn{3}{|c|}{ Constant uncertainty case } \\
\hline \multirow{4}{*}{ 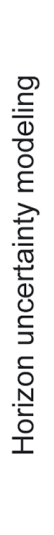 } & \multirow{2}{*}{ Trend } & Uncertainty trend & $0.33 \%$ & \multicolumn{3}{|c|}{$0.33 \%$} \\
\hline & & Modeling method & Bayesian kriging & \multicolumn{3}{|c|}{ Bayesian kriging } \\
\hline & \multirow[t]{2}{*}{ Residual } & $\begin{array}{l}\text { Vertical residual } \\
\text { uncertainty }\end{array}$ & 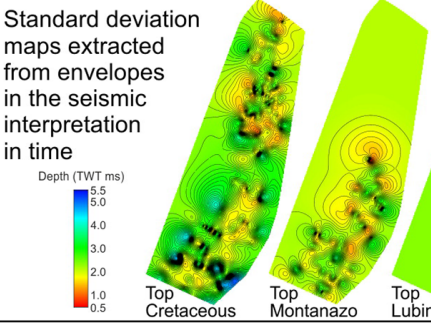 & $\begin{array}{l}\text { Constant } \\
\text { values for } \\
\text { each } \\
\text { horizon }\end{array}$ & $\begin{array}{l}\text { Top Model } \\
\text { Top Upper BTG Lubina } \\
\text { Top Lower BTG Lubina } \\
\text { Top BTG Montanazo } \\
\text { Top Cretaceous } \\
\text { Base Model }\end{array}$ & $\begin{array}{l}5.3 \mathrm{~m} \\
4.2 \mathrm{~m} \\
4.4 \mathrm{~m} \\
5.8 \mathrm{~m} \\
6.5 \mathrm{~m} \\
5.8 \mathrm{~m}\end{array}$ \\
\hline & & \begin{tabular}{|c|} 
Horizontal residual \\
uncertainty
\end{tabular} & $\begin{array}{l}\text { Variogram range }=500 \mathrm{~m} \\
\text { Spherical variogram function }\end{array}$ & \multicolumn{3}{|c|}{$\begin{array}{l}\text { Variogram range }=500 \mathrm{~m} \\
\text { Spherical variogram function }\end{array}$} \\
\hline \multicolumn{3}{|c|}{$\begin{array}{c}\text { Fault } \\
\text { uncertainty } \\
\text { modeling }\end{array}$} & $\begin{array}{l}\text { Variable distances. } \\
\text { Extracted from } \\
\text { envelopes } \\
\text { in the seismic } \\
\text { interpretation } \\
\text { in time }\end{array}$ & $\begin{array}{l}\text { Constant } \\
\text { values for } \\
\text { each } \\
\text { fault }\end{array}$ & $\begin{array}{l}\text { Same values for footwa } \\
\text { and hanging walls } \\
\text { Minimum radius } \\
\text { Maximum radius } \\
\text { Mean radius } \\
\text { Median radius }\end{array}$ & $\begin{array}{l}\text { alls } \\
17.3 \mathrm{~m} \\
36.5 \mathrm{~m} \\
28.2 \mathrm{~m} \\
28.8 \mathrm{~m}\end{array}$ \\
\hline
\end{tabular}

Figure 5. Parameters, values and methods used in the manual and constant uncertainty cases to capture the horizon and the fault uncertainties.
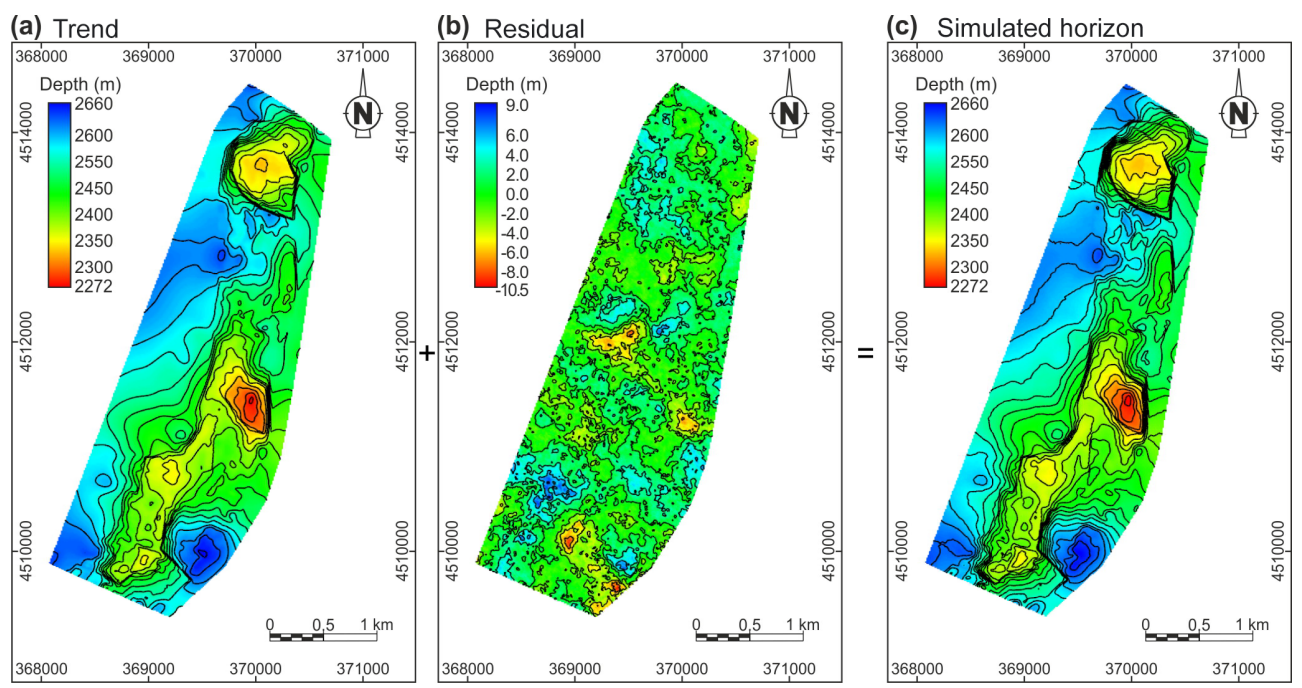

Figure 6. (a) Trend capturing the large-scale variation in the location and shape of the horizon. (b) Residual reproducing the small-scale or local variations between the trend and the unknown true depth of the horizon. (c) Simulated horizon that results from the sum of the trend and the residual. The example corresponds to the top of the Cretaceous. See also Fig. 7 for more details.

uncertainty, and a new horizon model (only one solution) is built (Fig. 7f). With this method, a prediction error or local depth uncertainty maps are obtained based on Bayesian updates of the uncertainty envelopes. The prediction error is at a minimum in the well locations, since the trend honors the well data, and increases away from the wells following the variogram (Fig. 8).
The stochastic simulation produces multiple realizations of the horizons, which represent the input uncertainty. The trend coefficients with which the trends are shifted are drawn from the posterior uncertainty distribution (Fig. $7 \mathrm{~g}$ ). Subsequently, the simulated residual field is adjusted to the wells with Bayesian kriging and added to the trend (Fig. 7h). 

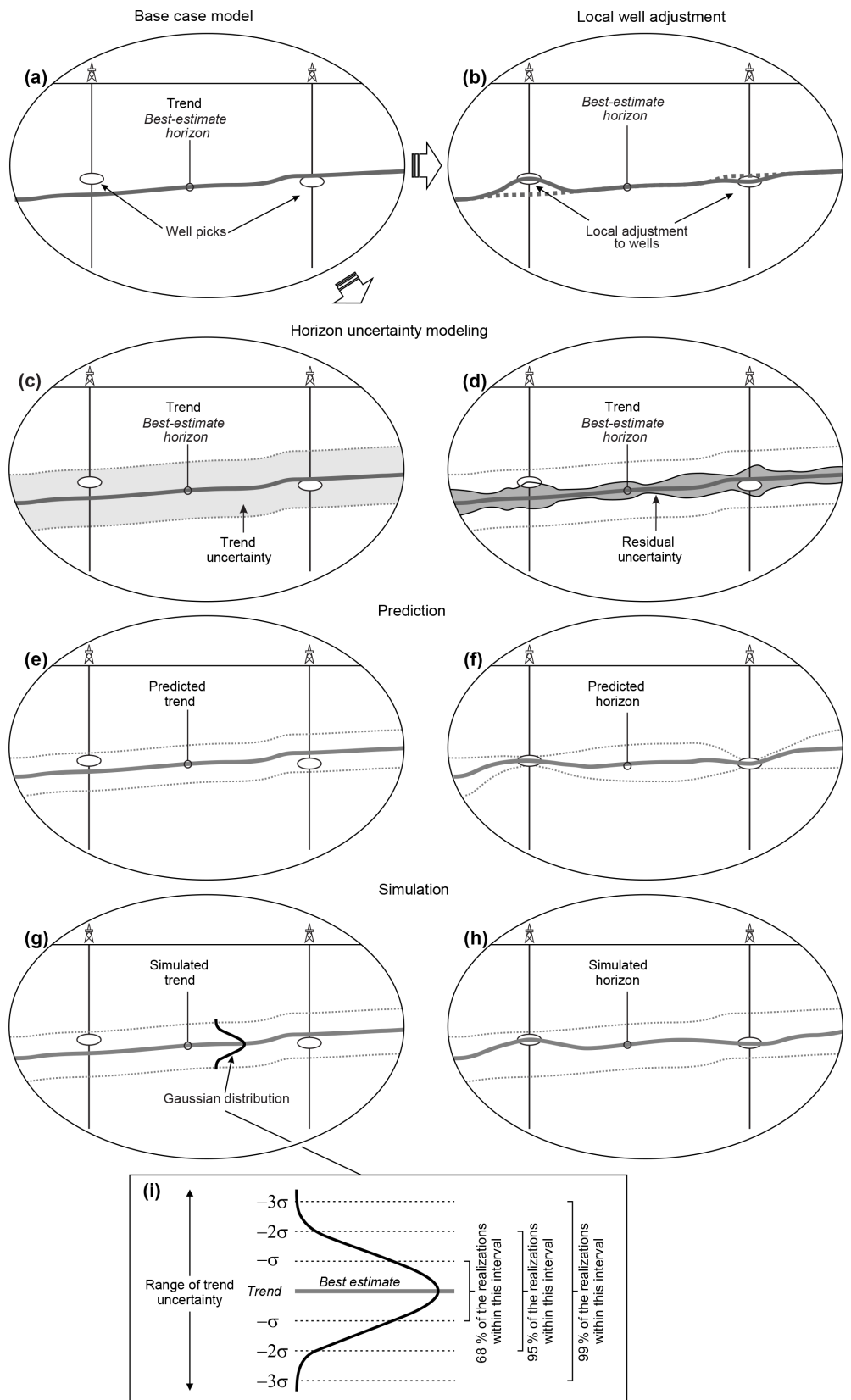

Figure 7. Diagram showing the steps of the horizons' uncertainty modeling. (a) Initial situation with the best-estimate interpretation of a horizon, which corresponds to the trend. This interpretation does not fit the well picks (i.e., wells observations, markers, well tops). (b) If the horizon uncertainty is not considered, typically the horizon interpretation is locally adjusted to the well picks. If the uncertainty is modeled, then the trend uncertainty range (c) and the residual uncertainty (d) are estimated. In the prediction method, the most like position of the trend is found (e) and the residual uncertainty is added to locally adjust the trend to the well picks (f). In simulation, a trend is simulated considering the trend uncertainty range and assuming a Gaussian distribution (g). Subsequently, the residual is included to add local variability and to adjust the horizon to the well observations (h). Since a Gaussian distribution is considered for modeling the trend, the estimation of the trend uncertainty range must consider the percentage of the realizations to be modeled within the selected range (i).

In the manual uncertainty workflow, the vertical residual uncertainty was defined using standard deviation maps extracted from the uncertainty envelope interpreted in the time domain (Fig. 5). Standard deviation values in the maps ranged from 3.23 to $5.49 \mathrm{~ms}$. In the constant uncertainty case, a constant standard deviation for each horizon was applied for the vertical residual uncertainty. Values between 4.2 and $6.54 \mathrm{~m}$, depending on the horizon, were used (Fig. 5). These values were estimated by obtaining the standard deviation of the averaged differences between the best-estimate interpre- 
(a) Manual uncertainty case
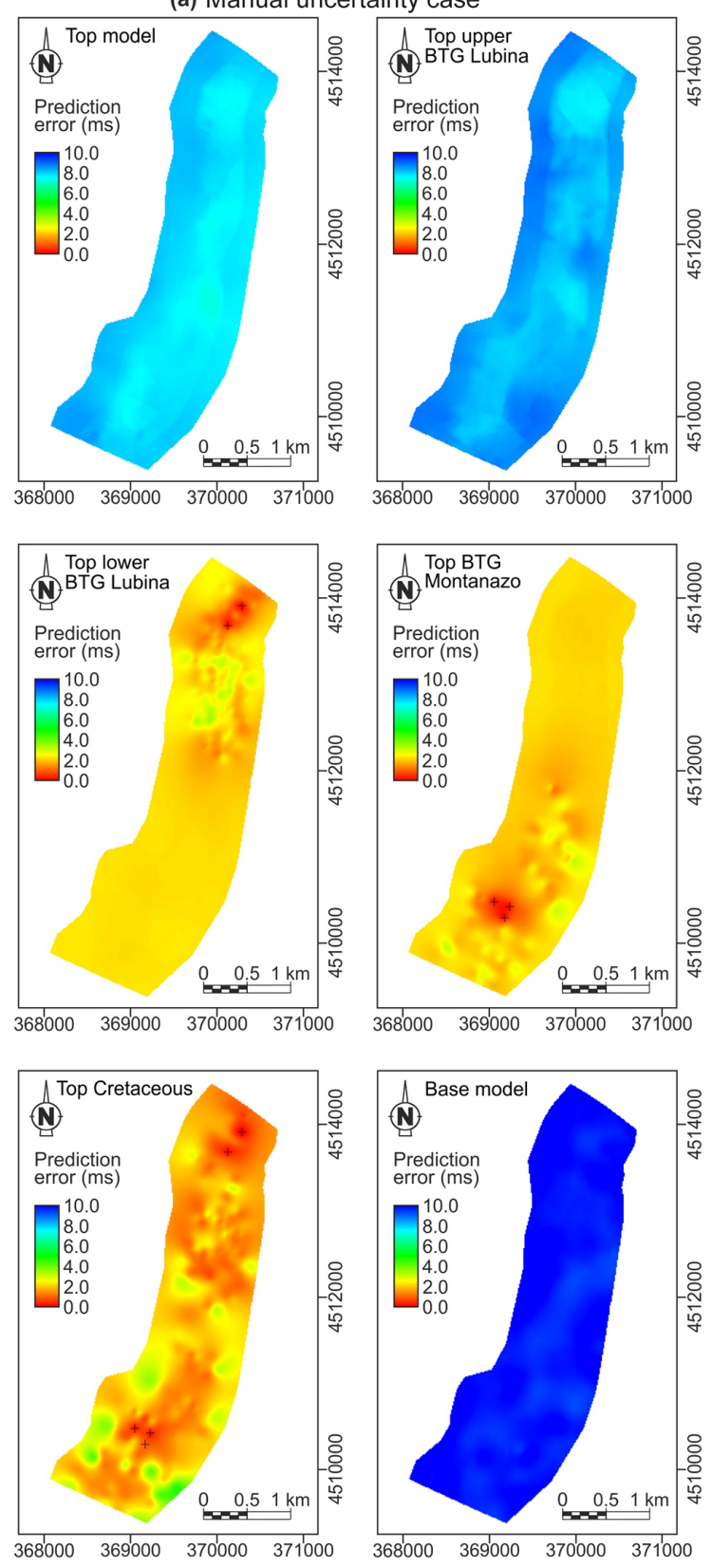

(b) Constant uncertainty case
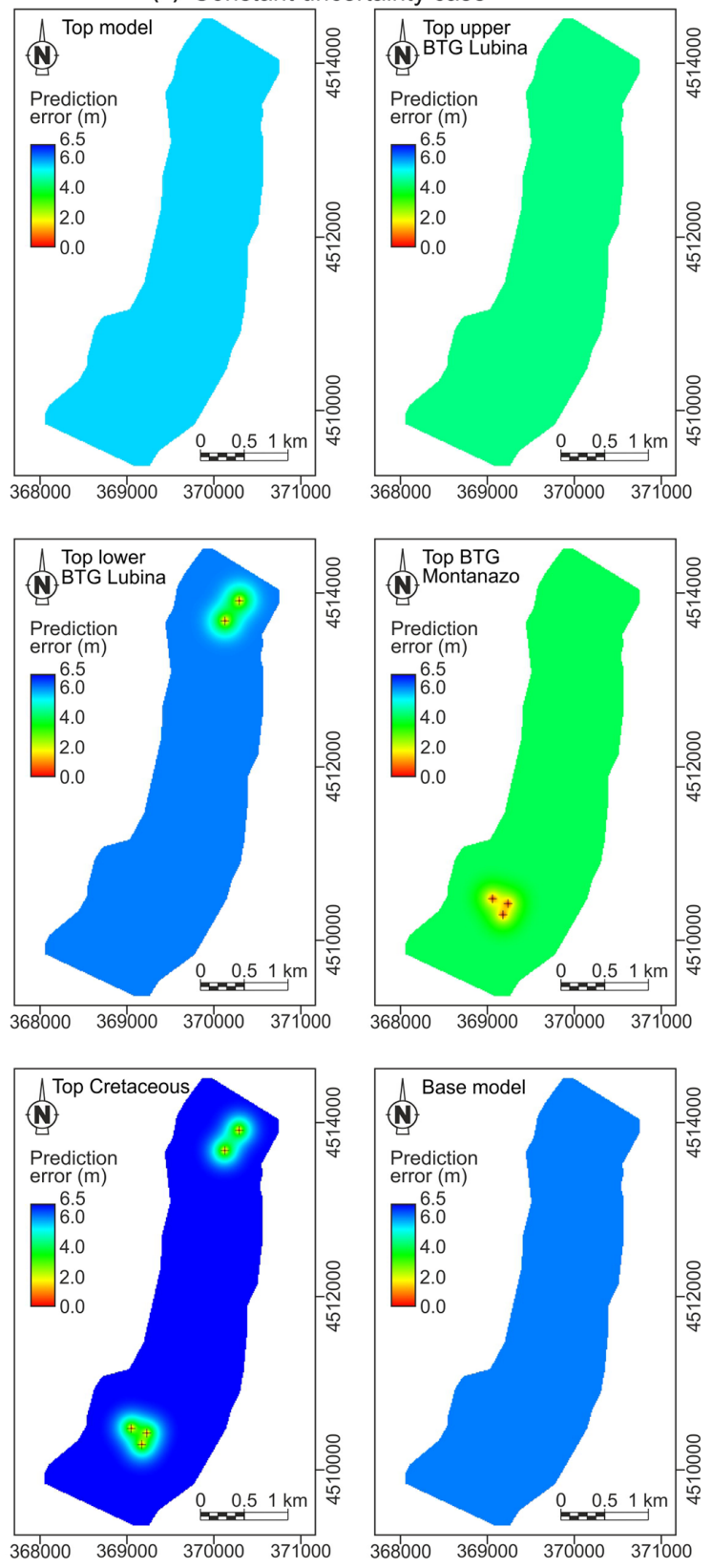

Figure 8. Horizon uncertainty maps obtained from the prediction method, describing the prediction error for all the horizons in (a) the manual and (b) the constant uncertainty cases. The top of the lower BTG in Lubina, the top of the BTG in Montanazo and the top of the Cretaceous have well picks available (indicated by crosses). For these horizons, the predicted errors are lower than for those without well picks (i.e., top model, top upper BTG Lubina and base model).

tation and the immediate zero amplitudes of reflectors in a number of sampled locations. For the spatial continuity of the residual uncertainty, a horizontal variogram range of $500 \mathrm{~m}$ was set for all the horizons to fit all data and a spherical variogram function was selected. In both workflows, a value of $0.3 \%$ of the trend was applied to set the trend uncertainty for all the horizons.
For the prediction method, the fault uncertainty was not modeled and only one solution of the structural model with the horizon uncertainty was built. For the simulation method, the horizon uncertainty modeling process was added to the structural model that captures the fault uncertainty to generate one horizon model for each realization of the fault model. In this way, one different structural model for each realiza- 
tion was obtained (i.e., final structural model in Fig. 3). We simulated 200 realizations of the structural model of each uncertainty modeling workflow. With this number of realizations, the fluctuations in the predicted GRV stabilize resulting in the output statistics being representative of the uncertainty captured. For the manual uncertainty case, which was based on the base case model in time, the horizons and faults in each realization were converted to the depth domain with the interval velocity model to obtain a final structural model. For the constant case, the uncertainty modeling workflow was entirely run in the depth domain.

\subsection{Three-dimensional grid and GRV}

For the base case structural model, for the prediction models and for each realization simulated, a 3-D grid was built. The corner point gridding method along with pillar gridding for faults (i.e., planar surfaces) was selected. In plan view, cell dimensions were set to $25 \mathrm{~m}$ by $25 \mathrm{~m}$, and vertically, the cell height was set to $20 \mathrm{~m}$. This resulted in 3-D grids with 1.5 million cells and approximately half a million defined cells. Each 3-D grid was quality controlled to verify the lack of collapsed cells.

Finally, the gross rock volume of the reservoir (i.e., Lower Cretaceous and BTG) above the OWC was estimated for the base case model, the prediction models and for each realization considering three scenarios: (a) the low case (proven case), where the OWC is at 2344 and at $2451 \mathrm{~m}$ below sea level in the Montanazo and Lubina culminations, respectively; (b) the intermediate case (probable case), with contacts at depths of 2360 and $2458 \mathrm{~m}$; and (c) the high case (possible case), with contacts at 2372 and $2465 \mathrm{~m}$.

\section{Results}

\subsection{Base case model}

The base case model of the Lubina and Montanazo fields shows a SW-NE oriented structural high, bounded by two major normal faults to the NW and SE (Fig. 9). Internally, other minor normal faults with a lower displacement and variable orientation compartmentalize the reservoir in multiple blocks. In the center of the area, a NW-SE-oriented fault separates the Lubina and Montanazo culminations.

The Montanazo culmination is approximately $2.4 \mathrm{~km}$ long and $0.8 \mathrm{~km}$ wide, and the Lubina culmination is $2.2 \mathrm{~km}$ long and $0.6 \mathrm{~km}$ wide. The BTG reservoir shows significant thickness changes throughout the field. In the Lubina culmination, both the upper and lower BTG reservoirs thins out towards the SSW, and the upper BTG pinches out few meters to the SSW of the Lubina-1 well position (Fig. 9c).

The maximum vertical thickness of the reservoir in the Montanazo culmination between the top of BTG Montanazo horizon and the OWC is $109 \mathrm{~m}$ in the low case, $125 \mathrm{~m}$ in the intermediate case and $137 \mathrm{~m}$ in the high case. In the Lu- bina culmination, the maximum vertical thickness recorded between the top of the upper BTG Lubina (i.e., top of the reservoir in this culmination) and the OWC is 133,140 and $147 \mathrm{~m}$ for the low, intermediate and high cases, respectively. Values of $80.5 \times 10^{6}, 101.6 \times 10^{6}$ and $122.6 \times 10^{6} \mathrm{~m}^{3}$ for the GRV above the OWC at the low, intermediate and high cases were estimated from the base case model (Fig. 10a).

\subsection{GRV in the prediction models and in the simulated realizations}

Changes in geometry, structure and dimensions of the reservoir in the Lubina and Montanazo culminations with respect to the base case model have been captured in the prediction models and in the 200 realizations of the manual and the constant uncertainty workflows. These variations impact on the GRV estimated, as is documented in Figs. 10 and 11. Figure 10a summarizes the results of the volume calculations for the prediction models and for realizations corresponding to the proved (i.e., P10), the probable (i.e., P50) and the possible (i.e., P90) scenarios, as well as complementary statistics. The GRV distribution for the 200 realizations obtained in the manual and in the constant cases for the three scenarios of the OWC depth are documented in the histograms of Fig. 10b and $\mathrm{c}$ and in the box plots of Fig. 11 that also shows the volumes for the base case and prediction models. In Fig. 12, the GRV distributions in the 3-D grids for a selection of models are presented.

Figures 13, 14 and 15 show three cross sections of the structural models for the manual and the constant uncertainty workflows. The realizations presented in the cross sections are those corresponding to P90, P50 and P10 of the GRV for the intermediate case of OWC depth (i.e., OWC at 2360 and $2458 \mathrm{~m}$ below sea level for the Montanazo and Lubina culminations, respectively). The cross section B-B' (Fig. 13) is a transect throughout the Montanazo culmination, whereas the cross sections C-C' (Fig. 14) and D-D' (Fig. 15) show the structure of the Lubina culmination in a southern and in a northern positions, respectively.

The GRVs estimated for the prediction model in the manual uncertainty case are $81.8 \times 10^{6} \mathrm{~m}^{3}$ for the low case, $103.2 \times 10^{6} \mathrm{~m}^{3}$ for the intermediate case and $124.5 \times 10^{6} \mathrm{~m}^{3}$ for the high case (Figs. 10a and 11). For the prediction model in the constant case, the estimated GRVs correspond to $81.6 \times 10^{6}, 102.8 \times 10^{6}$ and $123.8 \times 10^{6} \mathrm{~m}^{3}$ for the three OWC scenarios. The mean GRVs of the 200 realizations in the manual uncertainty case are $80.4 \times 10^{6} \mathrm{~m}^{3}$ for the low case, $101.6 \times 10^{6} \mathrm{~m}^{3}$ for the intermediate case, and $122.7 \times 10^{6} \mathrm{~m}^{3}$ for the high case. For the constant uncertainty case, the mean GRVs are slightly lower: $77.7 \times 10^{6} \mathrm{~m}^{3}$ for the low case, $98.4 \times 10^{6} \mathrm{~m}^{3}$ for the intermediate case and $118.9 \times 10^{6} \mathrm{~m}^{3}$ for the high case. The medians for all simulation cases are very close to the respective mean value, with maximum differences of $0.5 \times 10^{6} \mathrm{~m}^{3}$ (Fig. $10 \mathrm{~b}, \mathrm{c}$ ). The ranges corresponding to differences between P10 and P90 of the GRV for 
(a)

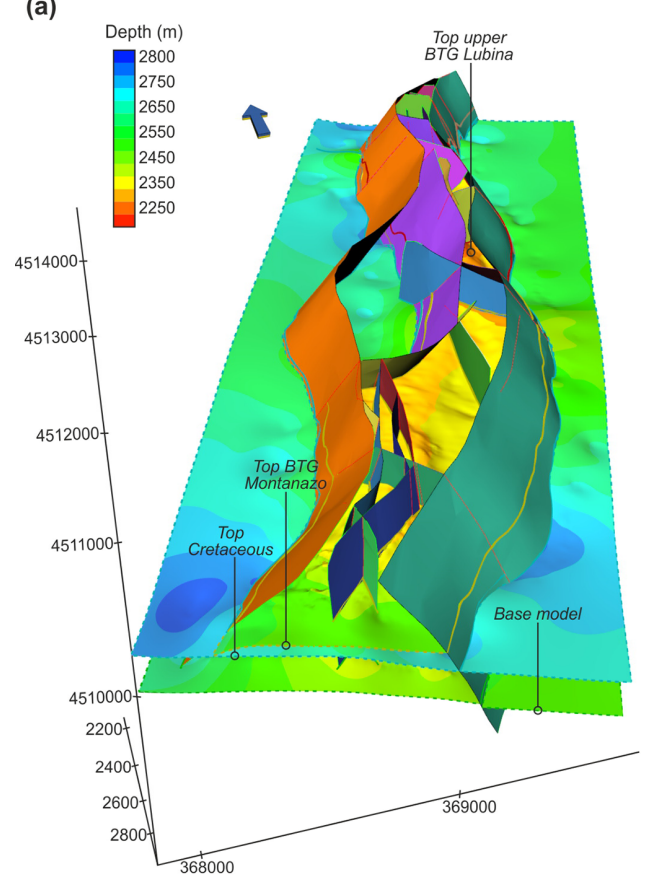

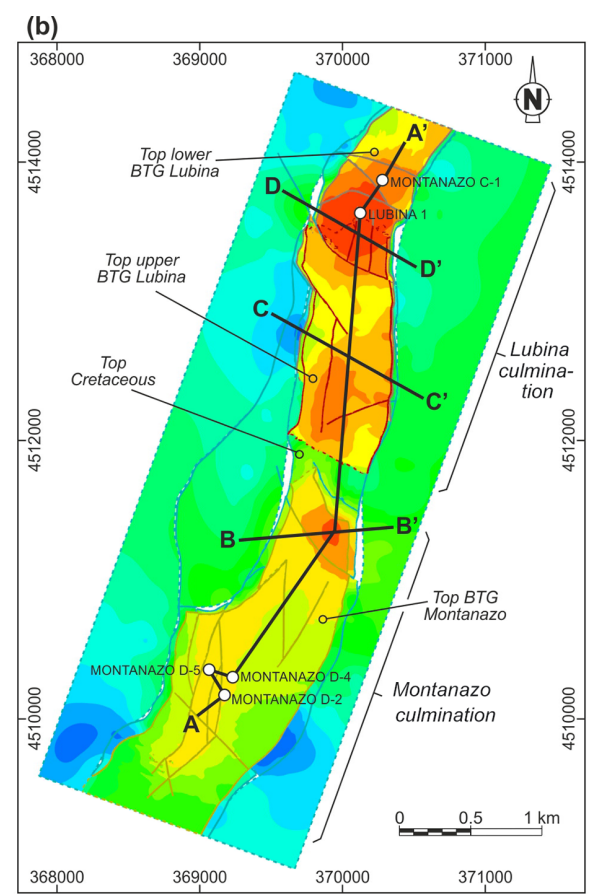

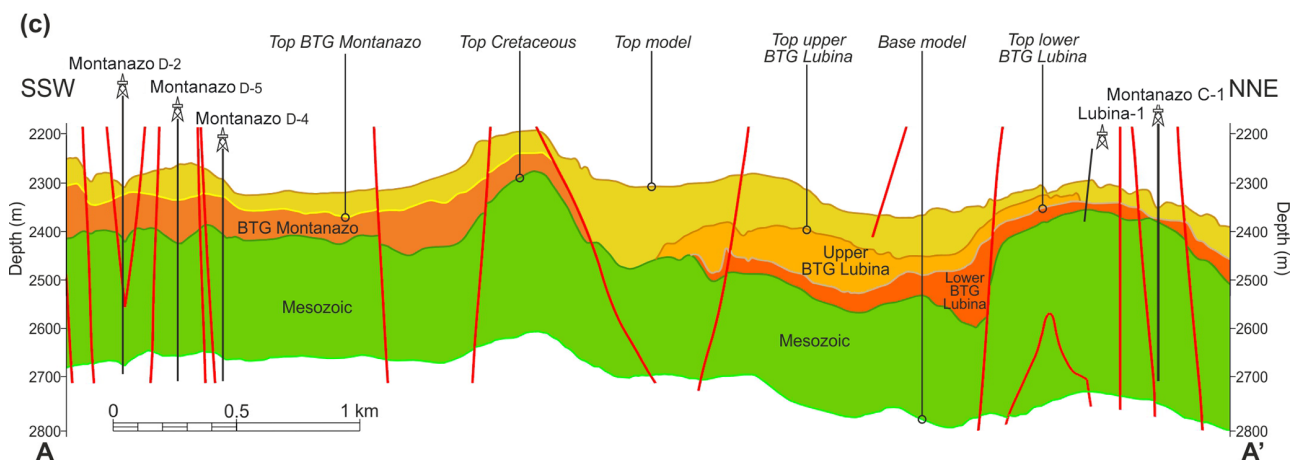

Figure 9. Base case structural model. (a) Three-dimensional view of the model showing the faults and the horizons reconstructed (with the exception of the uppermost top model horizon). (b) Map view of the model showing the horizons bounding the reservoir to the top. The location of cross sections A-A', B-B', C-C' and D-D' presented in panel (c) and in Figs. 13, 14 and 15, respectively, are shown. The position of the wells are also indicated. (c) Cross section A-A' of the base case model showing the structure of the reservoir. Note that the Lubina and Montanazo culminations are disconnected.

the manual and the constant uncertainties are, respectively, $12.6 \times 10^{6}$ and $15.3 \times 10^{6} \mathrm{~m}^{3}$ for the low case, $13.9 \times 10^{6}$ and $17.6 \times 10^{6} \mathrm{~m}^{3}$ for the intermediate case, and $15.0 \times 10^{6}$ and $20.0 \times 10^{6} \mathrm{~m}^{3}$ for the high case (Figs. 10a and 11).

\section{Discussion}

\subsection{Manually interpreted versus constant uncertainty cases}

The prediction method yielded similar responses in the GRV from both workflows, with GRVs between $1 \%$ and $1.6 \%$ higher than the base case in all the OWC depth scenarios
(Fig. 11). The relatively low impact on the GRV predicted is attributed to the fact that the prediction method applied only captures the horizon uncertainty, not the fault uncertainty, and only the most likely horizon position is modeled, which may blur the difference between the workflows compared.

The GRV values obtained from the 200 realizations of each of the modeling scenarios considered show a distribution that is close to normal, as indicated by mean values very close to the median and the bell shape of the calculated histograms (Fig. 10). Thus, the predicted GRV in each scenario can be considered as representative of the variability that the structural uncertainty estimation can generate with regard to an initial best-estimate structure. 
(a)

\begin{tabular}{|c|c|c|c|c|}
\hline \multicolumn{3}{|c|}{ Base case model } & \multicolumn{2}{|c|}{80.5} \\
\hline \multicolumn{3}{|c|}{$\begin{array}{c}\text { Manual } \\
\text { uncertainty case }\end{array}$} & \multicolumn{2}{|c|}{$\begin{array}{c}\text { Constant } \\
\text { uncertainty case }\end{array}$} \\
\hline Pre & iction & 81.8 & & 81.7 \\
\hline \multirow{7}{*}{ 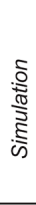 } & P90 & 73.7 & P90 & 69.8 \\
\hline & P50 & 80.8 & P50 & 77.5 \\
\hline & P10 & 86.3 & P90 & 85.1 \\
\hline & Minimum & 65.2 & Minimum & 60.4 \\
\hline & Maximum & 95.6 & Maximum & 93.8 \\
\hline & Mean & 80.4 & Mean & 77.7 \\
\hline & Median & 80.8 & Median & 77.4 \\
\hline
\end{tabular}

\begin{tabular}{|c|c|c|c|}
\hline \multicolumn{4}{|c|}{ Intermediate case GRV $\left(10^{6} \mathrm{~m}^{3}\right)$} \\
\hline \multicolumn{2}{|c|}{ Base case model } & \multicolumn{2}{|l|}{101.6} \\
\hline \multicolumn{2}{|c|}{$\begin{array}{c}\text { Manual } \\
\text { uncertainty case }\end{array}$} & \multicolumn{2}{|c|}{$\begin{array}{c}\text { Constant } \\
\text { uncertainty case }\end{array}$} \\
\hline & 103.2 & P90 & 102.7 \\
\hline P90 & 94.3 & P90 & 89.4 \\
\hline P50 & 102.1 & P50 & 98.6 \\
\hline $\mathrm{P} 10$ & 108.3 & $\mathrm{P} 10$ & 107.0 \\
\hline Minimum & 85.0 & Minimum & 79.6 \\
\hline Maximum & 118.1 & Maximum & 115.8 \\
\hline Mean & 101.6 & Mean & 98.4 \\
\hline Median & 102.1 & Median & 98.6 \\
\hline
\end{tabular}

\begin{tabular}{|c|c|c|c|}
\hline \multicolumn{4}{|c|}{ High case GRV $\left(10^{6} \mathrm{~m}^{3}\right)$} \\
\hline \multicolumn{2}{|c|}{ Base case model } & \multicolumn{2}{|l|}{122.6} \\
\hline $\begin{array}{l}\text { Manu } \\
\text { uncertainty }\end{array}$ & $\begin{array}{l}\text { lal } \\
y \text { case }\end{array}$ & $\begin{array}{r}\text { Consta } \\
\text { uncertainty }\end{array}$ & ant \\
\hline & 124.5 & & 123.9 \\
\hline P90 & 114.9 & P90 & 108.6 \\
\hline P50 & 123.1 & P50 & 119.4 \\
\hline $\mathrm{P} 10$ & 129.9 & P10 & 128.7 \\
\hline Minimum & 104.8 & Minimum & 98.9 \\
\hline Maximum & 140.2 & Maximum & 138.0 \\
\hline Mean & 122.7 & Mean & 118.9 \\
\hline Median & 123.1 & Median & 119.4 \\
\hline
\end{tabular}

(b)
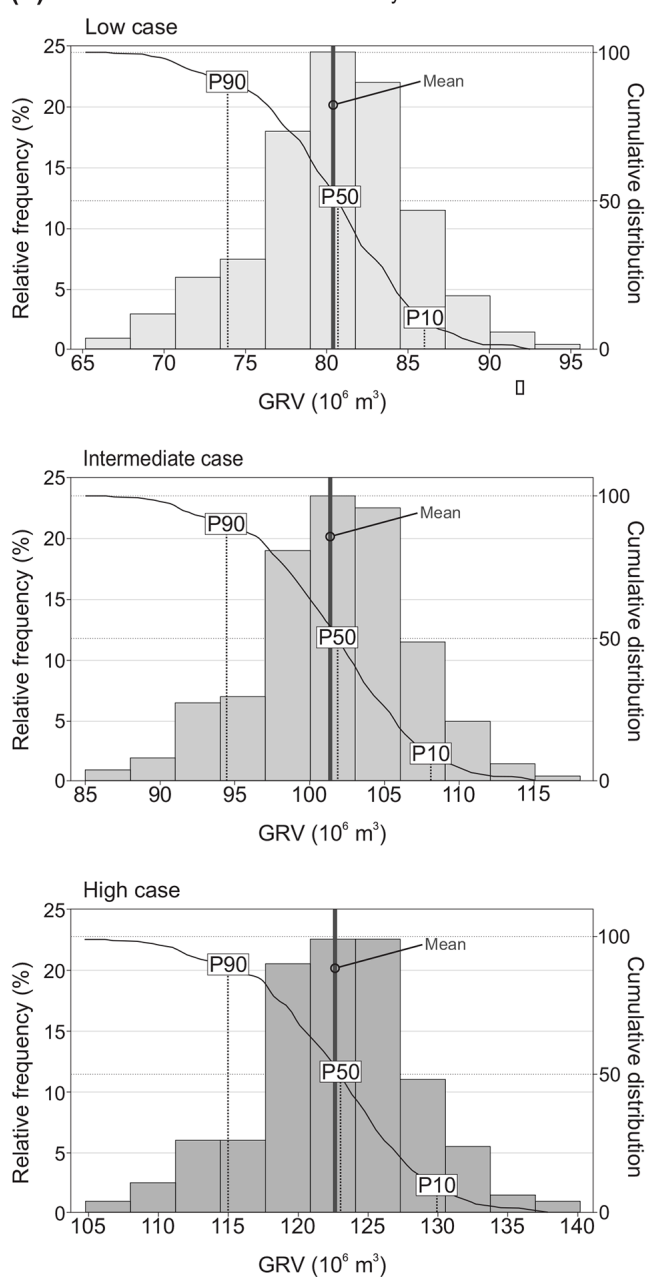

(c)

Constant uncertainty case
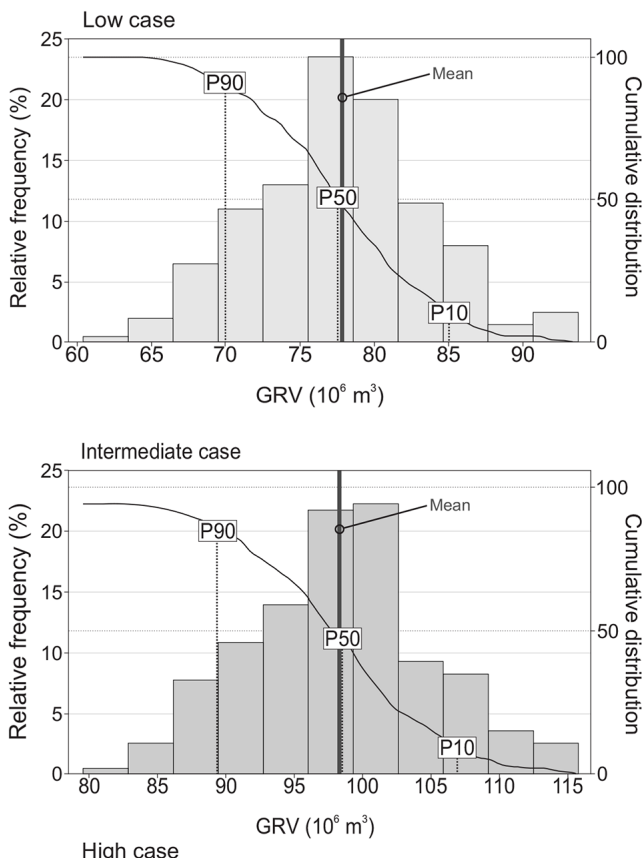

High case

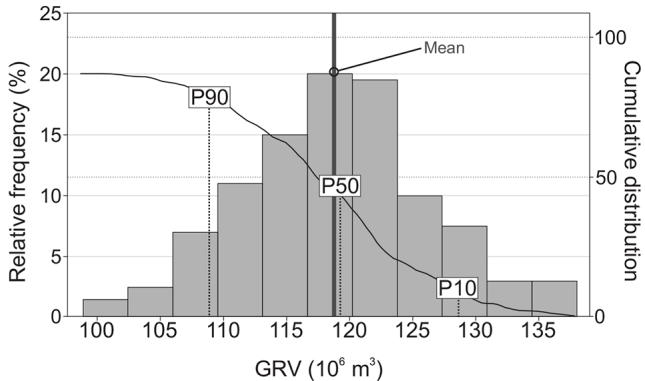

Figure 10. Gross rock volumes (GRVs) calculated from the models obtained with the manual and the constant uncertainty workflows. (a) GRV of the base case model, of the predicted models and of realizations corresponding to the proved (P90), probable (P50) and possible (P10) for the manual and the constant uncertainty cases in the low, intermediate and high oil-water contact depth cases. The minimum, maximum, mean and median for all simulation cases are also reported. Histograms showing the GRV distribution obtained from the 200 realizations (simulation method) of (b) the manual uncertainty case and of (c) the constant uncertainty case for the three oil-water contact depth cases. The mean GRVs in all cases are also indicated. 


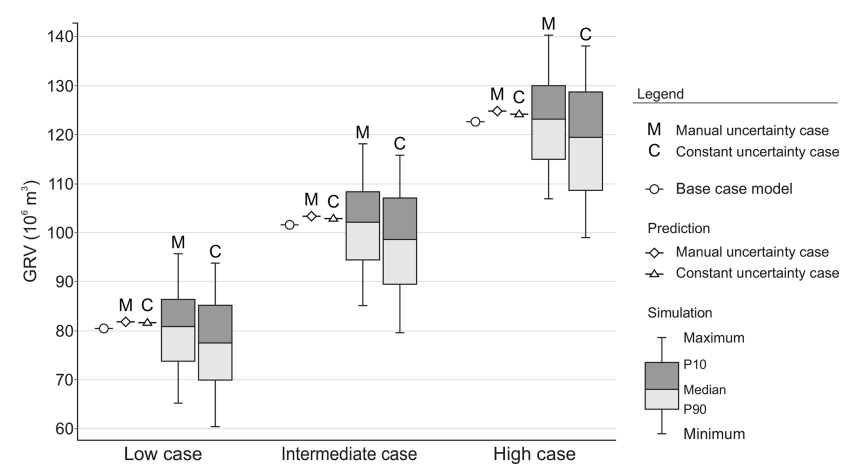

Figure 11. Box plots of the GRV obtained from the 200 realizations (simulation method) of the manual and the constant uncertainty cases for the low, intermediate and high oil-water contact depths. The GRVs of the base case and prediction models are also indicated.

Significant differences between the manual and the constant uncertainty workflows were recorded in the GRV distributions of the simulated realizations (Figs. 10 and 11).

- The mean and median GRVs for the constant uncertainty case are below the GRV in the base case model for the three scenarios of the OWC depth. By contrast, in the manual uncertainty case, the mean and median are higher than the base case GRV but very close to it.

- The P10, P90, and minimum and maximum GRV values (in addition to the median) are lower in the constant than in the manual uncertainty case. So, in general, lower GRV values are recorded for the constant than for the manual uncertainty cases.

- The ranges between P10 and P90 values in the constant uncertainty case are systematically higher (between 2.7 and $5.0 \times 10^{6} \mathrm{~m}^{3}$ ) than in the manual uncertainty case. This indicates a higher dispersion of the results in the former case.

The same uncertainty trend value and kriging method for the trend simulation and the same variogram range for the horizontal residual uncertainty were applied in both the manual and the constant uncertainty workflows. Hence, the differences in the GRV observed in both cases is expected to result from the envelopes around the horizon and fault interpretations.

Finding the right level for the residual uncertainties can be a challenging task that requires many iterations and detailed knowledge of the data. As the choice of residual uncertainty has a large impact on the simulated horizons, this choice will also affect the GRV estimates. However, by capturing the uncertainty as envelopes while interpreting, we get a more consistent representation of the uncertainties directly from the seismic data.

Differences attributed to the type of uncertainty envelopes defined are also recorded in the uncertainty maps describ- ing the prediction error obtained from the prediction models (Fig. 8). In both the manual and the constant cases, the prediction errors are low in the well locations for those horizons with well data available and higher predicted errors are recorded for those horizons without well picks available (i.e., top model, top upper BTG Lubina and base model), as expected.

\subsection{Impact of the structural uncertainty in a small and fractured reservoir}

Our study focuses on a small and highly fractured reservoir, which exhibits significant thickness changes and irregular horizon geometries (Figs. 9 and 13 to 15). GRVs predicted from the realizations in the manual and constant uncertainty cases estimate significant variations in GRV with respect to those calculated from the base case model (Figs. 11 and 12). In terms of percentage difference, the P10 and P90 realizations record mean values that are, respectively, $6.6 \%$ higher and $7.3 \%$ lower the GRV in the base case for the manual case considering the three OWC depth scenarios. Mean differences in the constant case are $12.2 \%$ lower and $5.3 \%$ higher than the GRV in the base case model.

As shown in Fig. 12a-e, for the same case of OWC depth (i.e., intermediate depth) and considering the realization corresponding to P50 of the GRV in the stochastic realizations, the variable extent of the oil zone is predicted amongst the base case, the prediction models and the simulated models. This is more prominent when considering realizations corresponding to the possible (P10) and proven (P90) scenarios. The realization corresponding to the proven volume in the manual case (Fig. 12g) shows that the Lubina culmination is not fully saturated in oil, since the central part is below the OWC in the intermediate depth, by contrast with the possible case in which almost the entire Lubina culmination is above the OWC (Fig, 12f). In one of the most optimistic scenarios represented by the possible case (P10) and the high OWC depth scenario (Fig. 12h), the oil zone covers almost the entire Lubina culmination (similarly to the realization P10 for the intermediate case; Fig. 12f) and, additionally, the oil zone in the Montanazo culmination widens towards the southeast. In the scenario corresponding to the proven volume (P90) and the low OWC depth case (Fig. 12i), the oil zone is significantly reduced.

The differences in the GRV and in the oil zone distribution that have been recorded by the uncertainty modeling workflows indicate that including the structural uncertainty associated with the picking of horizons and faults can be relevant to predictions derived from the structural model, even for small reservoirs with a relatively well-constrained structure.

The differences in the GRV can be, to some degree, correlated with variations in the reservoir structure (Figs. 13 to 15). It can be noted that the distance between the major NE-SW-oriented faults that limit the reservoir laterally 


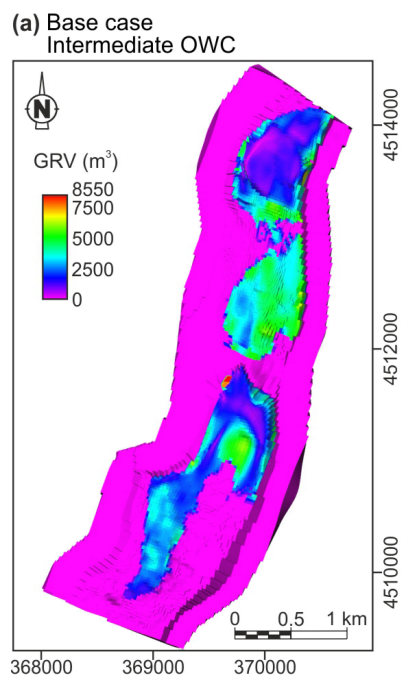

(d) Simulation: manual case (P50)

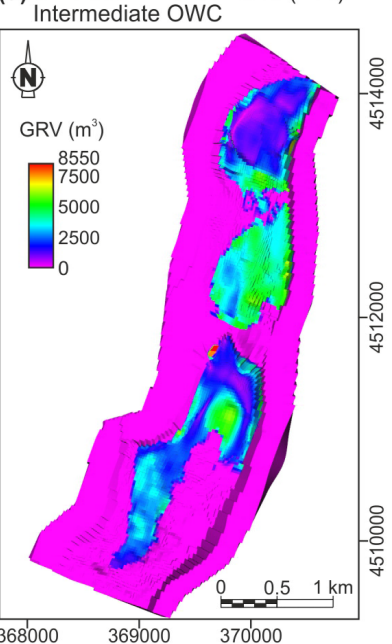

(g) Simulation: manual case (P90)

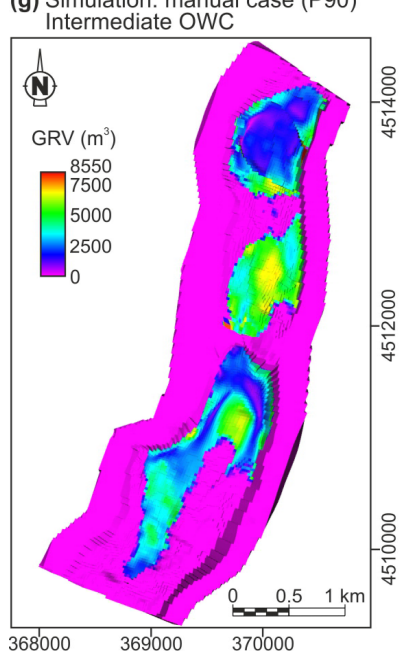

(b) Prediction: manual case

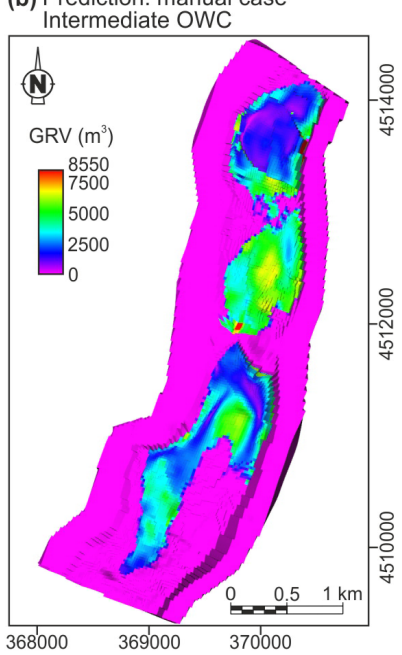

(e) Simulation: constant case (P50)

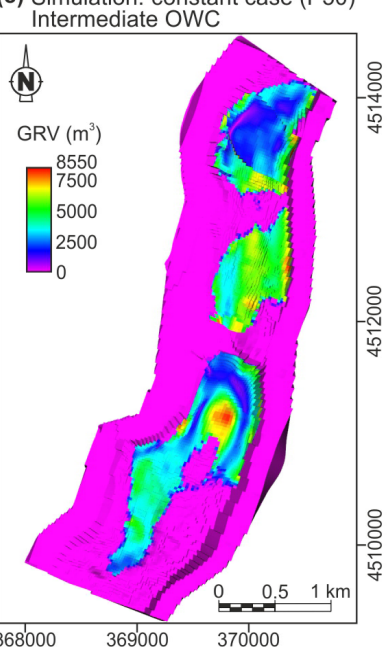

(h) Simulation: manual case (P10)

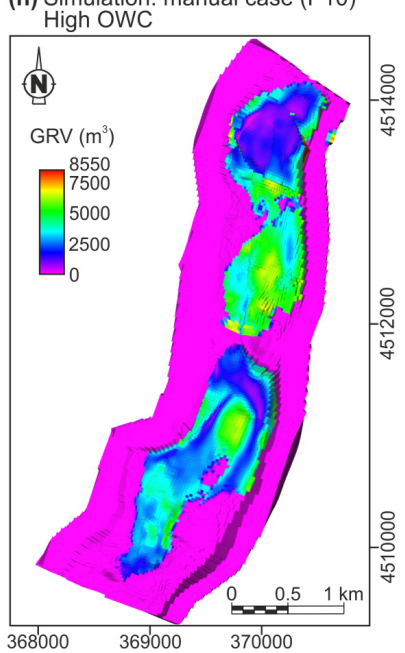

(c) Prediction: constant case

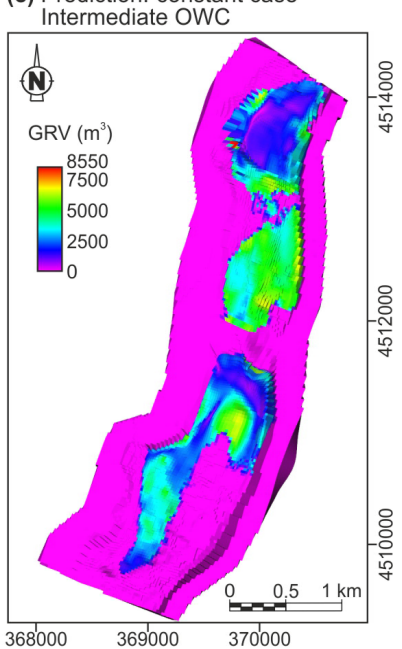

(f) Simulation: manual case (P10)

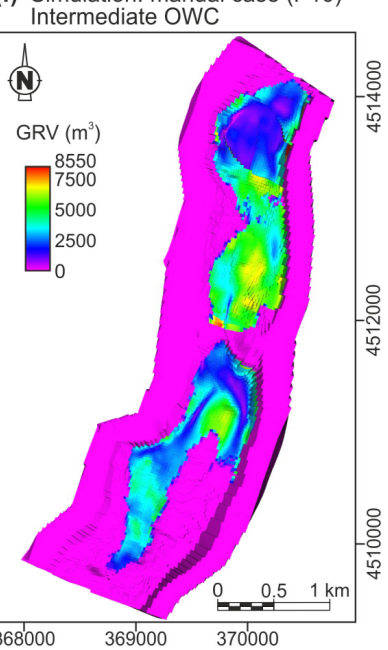

(i) Simulation: manual case (P90)

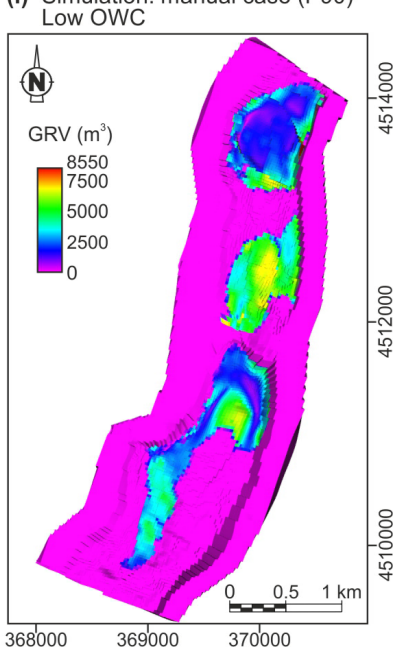

Figure 12. Top view of the 3-D grids with the oil gross volume distribution for (a) the base case model; the prediction method for (b) the manual and (c) the constant uncertainty case; the P50 realization of (d) the manual and (e) the constant uncertainty cases; (f) the P10 (possible volume) and (g) the P90 (proven volume) for the manual uncertainty case, in the intermediate OWC depth scenario. (h) The P10 in the high OWC scenario, and (i) the P90 in the low OWC scenario for the manual uncertainty case. 

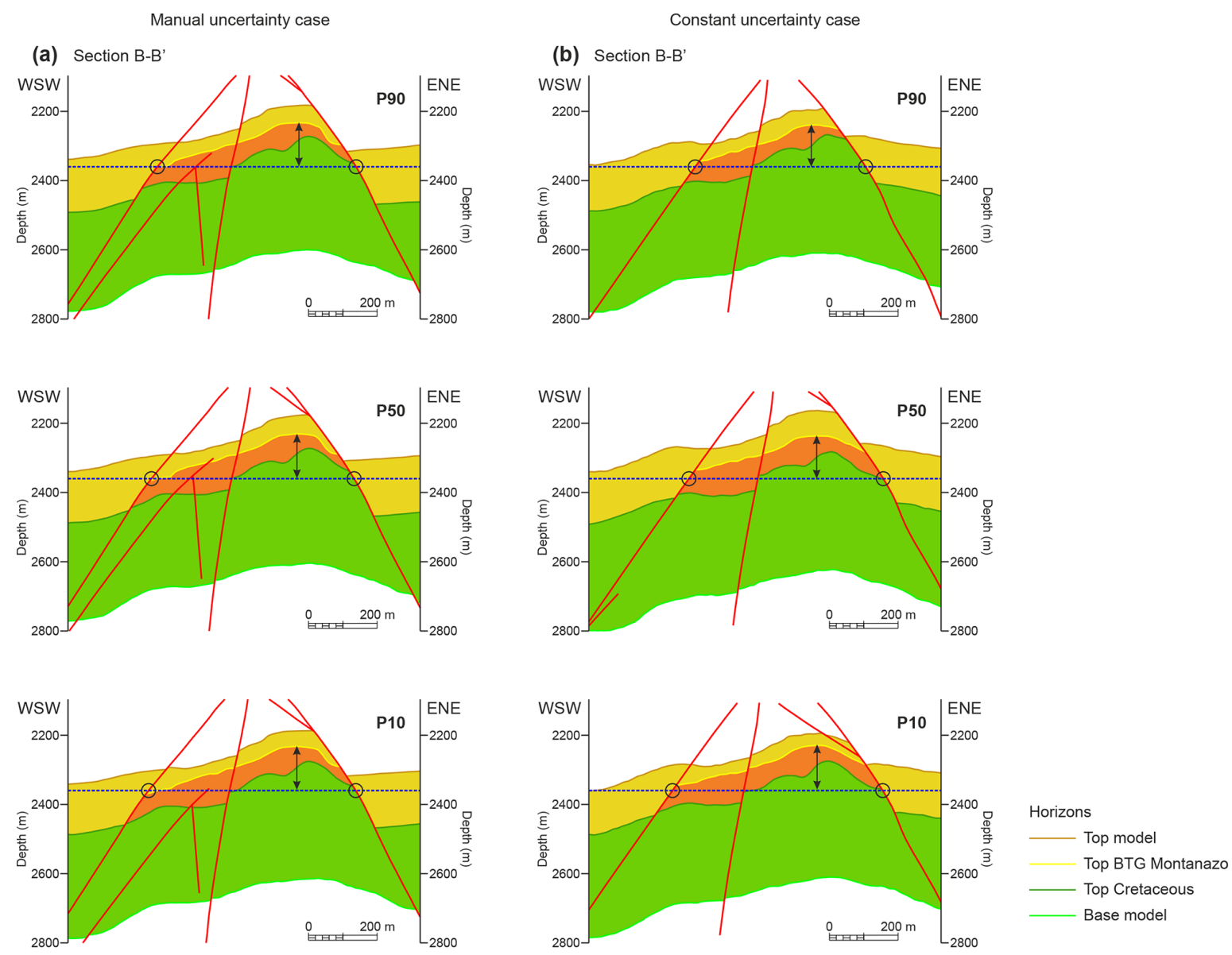

(c)

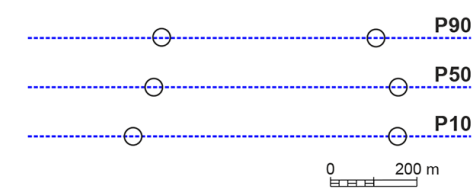

Modeling zones

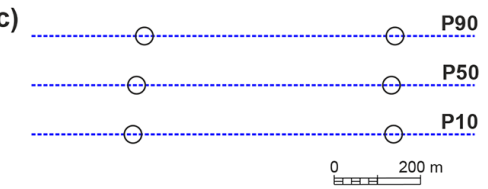

(d)
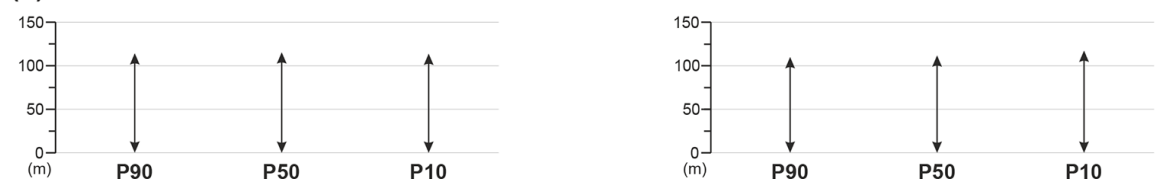

Above BTC

BTG Montanazo

Mesozoic

Faults

Oil-water contact at the intermediat depth case

Intersection between

faults and the oil-water contact at the intermediate depth case

Figure 13. Cross section B-B' of the structural model at the Montanazo culmination for the intermediate oil-water contact depth case showing the realizations corresponding to the proved (P90), probable (P50) and possible (P10) scenarios of the manual (a) and the constant (b) uncertainty cases. (c) Diagrams showing the position of the intersection between the major faults bounding the reservoir laterally and the oil-water contact for the P90, P50 and P10 scenarios. (d) Diagrams showing the maximum vertical distance between the reservoir top and the oil-water contact for the P90, P50 and P10 scenarios. Vertical exaggeration is $2 \times$. See the position of the section in Fig. $9 b$.

(see Fig. 9a, b) increases from realization P90 (proven case) to realization P10 (probable case) (Figs. 13c, 14c and 15c). Therefore, the greater separation of the major faults owing to their lateral displacement within the fault uncertainty envelope leads to an increase in the width of the reservoir with the result of enhancing the predicted GRV. This fact indicates that the fault uncertainty in major faults strongly impacts the GRV in the reservoir.
By contrast, no systematic variation in the positions of the horizons (i.e., decreasing or increasing depth) has been observed comparing the P10, P50 and P90 realizations in Figs. $13 \mathrm{~d}, 14 \mathrm{~d}$ and $15 \mathrm{~d}$. This is as expected, as the residual Gaussian field has an expectation of zero, and the uncertainty of the trend is relatively low. 

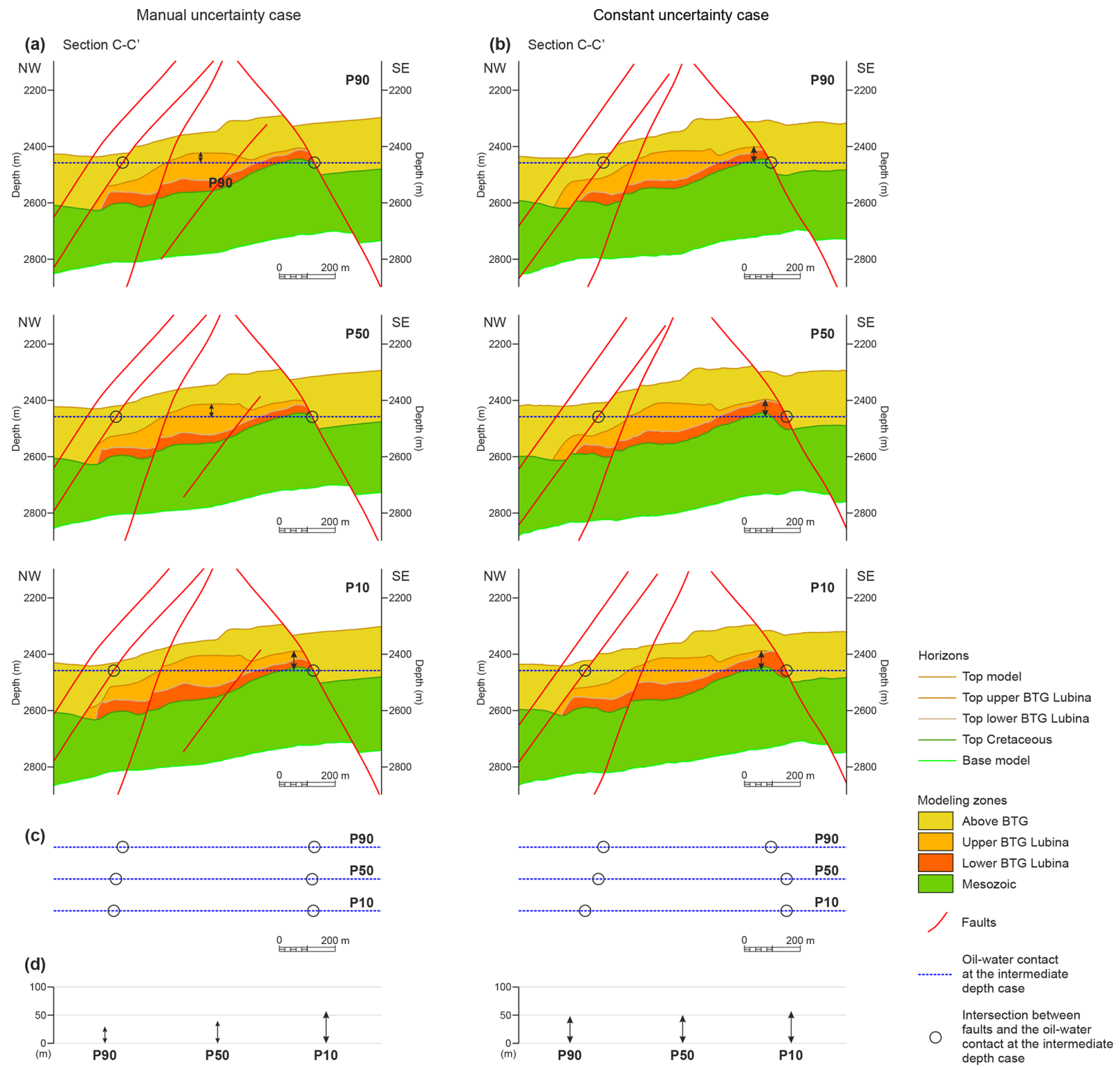

Figure 14. Cross section C-C' of the structural model in the southern sector of the Lubina culmination for the intermediate oil-water contact depth case showing the realizations corresponding to the proved (P90), probable (P50) and possible (P10) scenarios of the manual (a) and the constant (b) uncertainty cases. (c) Diagrams showing the position of the intersection between the major faults bounding the reservoir laterally and the oil-water contact for the P90, P50 and P10 scenarios. (d) Diagrams showing the maximum vertical distance between the reservoir top and the oil-water contact for the P90, P50 and P10 scenarios. Vertical exaggeration is $2 \times$. See the position of the section in Fig. $9 b$.

\subsection{Seismic survey and other sources of structural uncertainty}

The structural uncertainty in horizon interpretation as captured in the presented workflow mainly depends on the type of seismic data used for the interpretation and on the depth of the reservoir. In this case study, the top of BTG Montanazo, top of the upper BTG Lubina and the top of the Cretaceous were interpreted as trough reflectors, whereas the top of the lower BTG Lubina was interpreted as the peak reflector im- mediately above the top of the Cretaceous in the Lubina culmination (Figs. 4 and 16). The horizons were picked in the center of the corresponding reflectors, where the amplitudes show the maximum or minimum values. The uncertainty envelopes for the manual interpretation were mainly defined according to the frequency content (i.e., the lower the frequency content, the higher the uncertainty envelope) and also considering lateral variations in the amplitude along the horizons. 

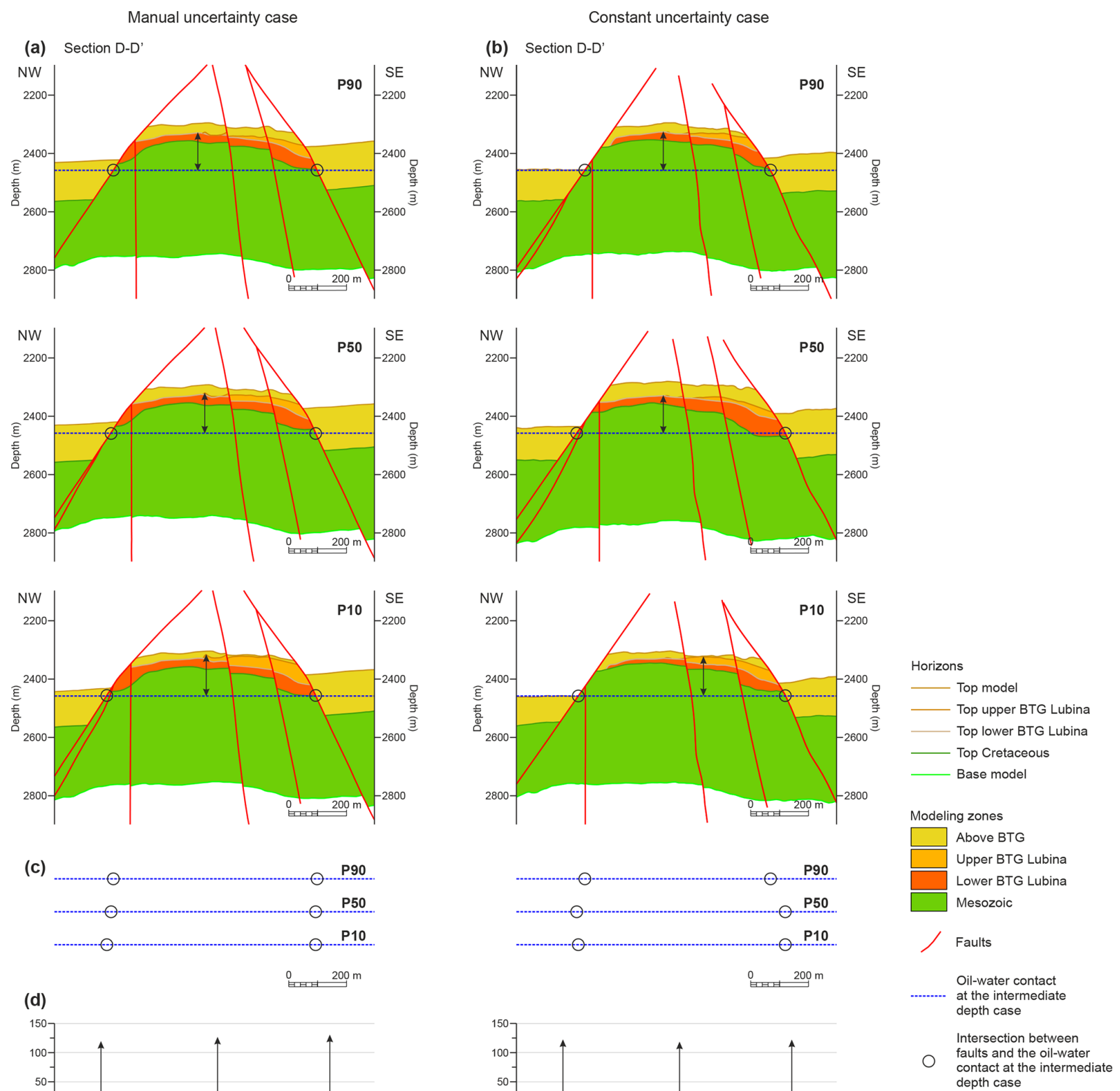

(c)
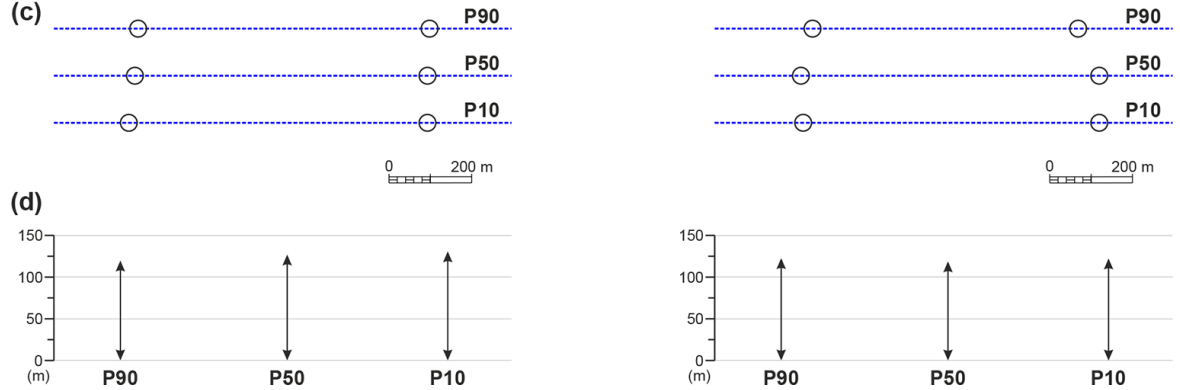
depth case

Figure 15. Cross section D-D' of the structural model in the northern sector of the Lubina culmination for the intermediate oil-water contact depth case showing the realizations corresponding to the proved (P90), probable (P50) and possible (P10) scenarios of the manual (a) and the constant (b) uncertainty cases. (c) Diagrams showing the position of the intersection between the major faults bounding the reservoir laterally and the oil-water contact for the P90, P50 and P10 scenarios. (d) Diagrams showing the maximum vertical distance between the reservoir top and the oil-water contact for the P90, P50 and P10 scenarios. Vertical exaggeration is $2 \times$. See the position of the section in Fig. 9b.

If the horizon uncertainty envelopes are mainly defined according to the frequency content and amplitudes, especial attention should be given to the seismic survey used when modeling the structural uncertainty in the seismic interpretation. Conventional survey with a narrow frequency band suffers from dominant side lobes in the wavelet. Visually, they seem to provide higher-frequency content and narrow reflection events, which are easy and often preferable to pick.
However, such events may not represent real elastic changes in the subsurface (Junbin et al., 2007), and thus, seismic interpretation based on this type of seismic survey will lead to overconfidence. By contrast, as broadband surveys contain more low-frequency information, the seismic image displays wider reflectors and picking visually might seem more ambiguous. At the same time, increased low-frequency content in such surveys provides higher resolution in the seismic, 

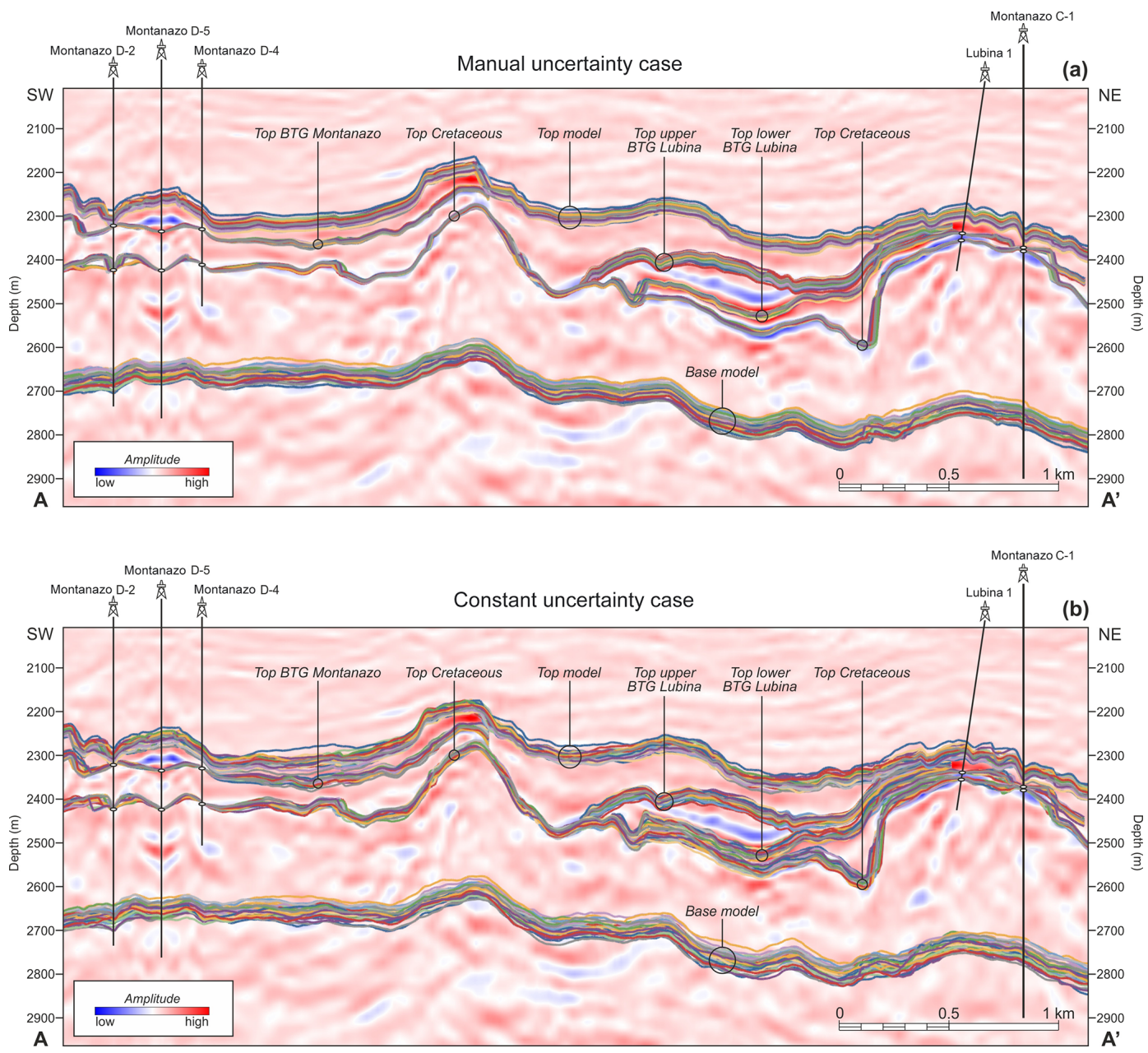

Figure 16. Multiple realizations of the horizons modeled by capturing the uncertainty using the manual and the constant uncertainty cases. Only 50 of the 200 realizations are shown in each case. Note that the uncertainty is nonexistent in the well positions for those horizons with well picks and that the horizons showing the maximum spread are those without well pick data available. It can also be appreciated that the spread of uncertainty is visually higher in the constant than in the manual uncertainty cases and that in both cases increases with the depth of the horizon.

which will improve the detection of certain elastic changes in the subsurface.

In the present case study, the seismic data used correspond to a conventional survey $(8-80 \mathrm{~Hz}$ bandwidth) with frequency content between 20 and $40 \mathrm{~Hz}$ and a vertical resolution of $45 \mathrm{~m}$. The maximum vertical thicknesses of the reservoirs measured from the reservoir top horizons to the OWC in the base case are 3 times the vertical resolution of the seismic data, and strong thickness variations occur throughout both the Montanazo and Lubina culminations. Thus, capturing the uncertainty in the position of the horizon within a reflector is relevant and justified in study cases like the one presented here.

Other sources of the structural uncertainty, such as the velocity and well uncertainty, are also relevant for modeling the reservoir structure. To broadly document the impact of the velocity model, we have rapidly assessed its uncertainty in depth using the error propagation formula (e.g., Taylor, 1997):

$z=V \cdot t$

$\varepsilon_{z}=\left|\frac{\partial z}{\partial V}\right| \varepsilon_{V}+\left|\frac{\partial z}{\partial t}\right| \varepsilon_{t}=t \cdot \varepsilon_{V}+V \cdot \varepsilon_{t}$,

where $z$ is depth, $V$ is velocity and $t$ is time of an event; $\varepsilon_{z}$, $\varepsilon_{V}$ and $\varepsilon_{t}$ are, respectively, the uncertainty in depth, in the velocity model and in time (or sampling time).

We used the top of the lower BTG Lubina in the Lubina culmination as an example to apply the calculation. The twoway travel time of the selected seismic event is $2.325 \mathrm{~s}$ and the corresponding velocity recorded in the velocity model is $4.5 \mathrm{~km} \mathrm{~s}^{-1}$. Considering that the uncertainty in the velocity model is up to $0.1 \mathrm{~km} \mathrm{~s}^{-1}$, and the uncertainty in time is $0.002 \mathrm{~s}$, then the maximum uncertainty in depth associated with the velocity model for this example is approximately 
$120 \mathrm{~m}$. In the formula used, the first term depends on the error associated with the velocity model. It is important to note that this term is the one contributing to a higher degree to the uncertainty in depth. For the selected horizon, the depth variation resulting from the uncertainty in the seismic interpretation in the Lubina culmination is approximately $35 \mathrm{~m}$ (see Fig. 16).

Further studies combining all sources of the structural uncertainty (seismic uncertainty, velocity model and well uncertainty) in one modeling workflow are required to provide a global estimation of the structural uncertainty for the Lubina and Montanazo fields. Moreover, a combined workflow will help to avoid any overestimation of the uncertainty effect that may happen when only one source is considered ("ballooning effect"). With the reservoir modeling software used, the uncertainty in the velocity model can be included in the horizon uncertainty modeling process using interval velocity maps and their associated uncertainty, along with well data uncertainty related to fault and horizon well picks, stratigraphic zone interpretation and well trajectories.

\subsection{Uncertainty modeling workflows}

We have modeled the structural uncertainty in picking horizons and faults using modern workflows, whose main advantages and limitations encountered in this study are discussed below.

The application of these workflows generate multiple realizations of the structural model that are all geologically consistent with the available data. Moreover, all realizations can be quickly updated when required, as for example when new fault and horizon interpretations are performed, when input data are changed, or when new well data are available.

The workflows consist of a chain of processes that can be easily designed. However, a previous knowledge of the data is necessary to set up the uncertainty modeling appropriately. The uncertainty trend should be defined according to the distance the horizons can be moved away from the original interpretation. Trend uncertainty values are typically up to $10 \%$ of the depth of the horizon (Emerson Automation Solutions, personal communication, 2015), but this can vary depending on the field and the amount of data available. As modeling the horizon uncertainty is directly related to the resolution of the seismic data, the trend uncertainty generally increases with depth (Fig. 16). The uncertainty drops to zero in the well locations (since the simulated horizons are adjusted to match the well picks) and gradually increases away from the wells according to the variogram settings (Fig. 16). Therefore, in reservoirs with few well data, it is especially relevant to capture the structural uncertainty.

The variogram ranges set for the residual uncertainty should in general not be more than the half of the reservoir size (Emerson Automation Solutions, personal communication, 2015), and accounts for the correlation of small-scale variations in the depths of the horizons. In this study, the variogram range was set to half of the reservoir width (i.e., $500 \mathrm{~m}$ ). The variogram function should be selected according to the degree of noise to be captured by the residual. Exponential functions are used for erratic scenarios, Gaussian variograms produce smooth results, and spherical functions (the variogram type used in this study) are in between both the exponential and Gaussian functions and tend to represent realistic scenarios in geosciences.

As documented and discussed above, manual interpretation of the uncertainty envelopes around faults and horizons will produce more accurate predictions of the uncertainty impact, although manual interpretation is always prone to human error and bias (Bond, 2015; Alcalde et al., 2017a; Schaaf and Bond, 2019). This method may appear more time-consuming than the constant uncertainty case, but finding the appropriate constants can be equally challenging and time consuming, if not even more so.

Adding the structural uncertainty in the modeling workflow has allowed us to evaluate its effects on the reservoir volume estimation in this case study. In further studies, the impact of the structural uncertainty can also be assessed on a variety of outcomes of the reservoir modeling process, such as facies proportions, recovery efficiency and water cut predictions, and in history matching. Additionally, as commented above, other sources of the structural uncertainty should also be investigated. Moreover, the structural uncertainty can be combined in the modeling workflow with the uncertainty associated with other parameters, such as porosity, fluid contacts, fluid saturations, fault seal or aquifer size to produce a set of possible scenarios whose variations account for all the uncertainties considered.

\section{Conclusions}

We have applied modern workflows to document the impact of the geophysical uncertainty on predicted GRVs in the small and highly fractured Lower Cretaceous and Tertiary reservoir of the Lubina and Montanazo fields (western Mediterranean Sea). The results obtained allowed us to conclude the following.

The reservoir exhibits significant thickness changes and irregular horizon geometries. It is laterally limited by major NE-SW-oriented normal faults, and, internally, it is compartmentalized into multiple blocks by other minor faults. The Montanazo and Lubina culminations are separated by a NWSE-oriented normal fault.

The uncertainty modeling workflows applied generate multiple realizations of the structural model which show differences in geometry and dimensions of the reservoir, but which are all geologically consistent with the available data. Capturing the structural uncertainty by producing multiple realizations allows us to improve the understanding of the reservoir structure. 
The structural uncertainty associated with the picking of horizons and faults in seismic data has a relevant impact on the volume estimation. The realizations capturing the structural uncertainty predict mean GRV percentage differences with respect to the GRV in the base case (the model from the best-estimate interpretation) that are up to $7 \%$ higher and $13 \%$ lower.

The two uncertainty modeling workflows tested in this study differ in the accuracy with which the uncertainty around the horizons and fault interpretations in the seismic data is defined. Capturing the uncertainty by defining manually the ambiguous zones around the interpreted surfaces in the seismic data reports narrower GRV predictions from the simulated structural models, more accurate horizon prediction errors and more consistent results than modeling the structural uncertainty with constant sizes for the ambiguous zones.

The major NE-SW-oriented normal faults that bound the reservoir laterally impact the GRV predicted from the simulated structural models to a larger extent.

The uncertainty envelopes in the horizon uncertainty modeling are mainly defined according to the frequency content and amplitudes, and, therefore, especial attention should be given to the seismic survey used.

Uncertainty in the horizons increases with depth (trend uncertainty) and with the absence of well picks available. Therefore, for those scenarios with few well data available, capturing the structural uncertainty is especially relevant.

The uncertainty modeling workflows applied are easy to design and allow us to update the models when required. As always, domain knowledge of the data is necessary to set up appropriately the uncertainty modeling workflows.

In next steps of the modeling, it may be significant to use a single workflow combining other sources of structural uncertainty (i.e., velocity uncertainty and well uncertainty) to obtain a more complete estimation of the structural uncertainty in the GRV. Covering the entire range of possible structural scenarios will help to understand better the geology of Lubina and Montanazo oil fields by adding more value to the simulation and history matching stages. This will lead to an improved field development decision making process. Furthermore, the grids constructed for each realization could be the base to build property models and further simulation, allowing all uncertainties to be preserved and, thus, the risk assessment to be improved.

Data availability. Data are subjected to a confidential agreement between Repsol and the University of Barcelona and are not deposited in a public repository.

Author contributions. AB and IA were responsible for the conceptualization of the research and $\mathrm{CG}$ for providing the original dataset and interpretation by Repsol. CPB and PC conducted the research, and along with the rest of the co-authors, performed the formal analysis of the results. PC, CPB and IA prepared the original paper which was reviewed and edited with contributions from all coauthors.

Competing interests. The authors declare that they have no conflict of interest.

Special issue statement. This article is part of the special issue "Understanding the unknowns: the impact of uncertainty in the geosciences". It does not belong to a conference.

Acknowledgements. Thanks are due to Emerson Automation Solutions for the donation of RMS licenses and for the technical support to use the software. We are indebted to Repsol for providing the dataset used and also for the support received. The constructive comments by Vedad Hadziavdic, Alexander Schaaf and Clare Bond are much appreciated and have improved the paper. Suggestions from Juanjo Ledo and Alex Marcuello also helped to enhance the paper.

Financial support. This research has been supported by the projects SALCONBELT (CGL2017-85532-P), SEROS (CGL201455900-P) and 3D-MODGHASY (RTI2018-097312-A-I00) (MCI/AEI/FEDER, UE) and by Generalitat de Catalunya (2017SGR596).

Review statement. This paper was edited by Clare Bond and reviewed by Vedad Hadziavdic and Alexander Schaaf.

\section{References}

Aarnes, I., Skorstad, A., and Kallekleiv, H.: Acknowledging structural uncertainties in the reservoir models - a consistent approach to improve subsurface predictions, Production Geoscience, Stavanger, Norway, 4-5 November 2014, 2014.

Abrahamsen, P.: Bayesian kriging for seismic depth conversion of a multi-layer reservoir, in: Quantitative Geology and Geostatistics, 5, edited by: Soares, A., Springer, Dordrecht, Netherlands, 385398, https://doi.org/10.1007/978-94-011-1739-5_31, 1993.

Abrahamsen, P.: FFT algorithm for simulating gaussian random fields, Norwegian Computing Center, Oslo, Norway, NR-note SAND/10/1999, 1999.

Abrahamsen, P.: Combining methods for subsurface prediction, in: Geostatistics Banff 2004, vol. 2, edited by: Leuangthong, O. and Deutsch, C. V., Springer, Dordrecht, Netherlands, 601-610, https://doi.org/10.1007/978-1-4020-3610-1_61, 2005.

Abrahamsen, P. and Benth, F. E.: Kriging with inequality constraints, Math. Geol., 33, 719-744, https://doi.org/10.1023/A:1011078716252, 2001. 
Abrahamsen, P., Dahle, P., Kvernelv, V. B., Sektnan, A., and Almendral Vazquez, A.: Cohiba User Manual Version 5.6, Norwegian Computing Center, Oslo, Norway, SAND/07/2018, 2018.

Alcalde, J., Bond, C. E., Johnson, G., Butler, R. W. H., Cooper, M. A., and Ellis, J. F.: The importance of the structural model availability on seismic interpretation, J. Struct. Geol., 97, 161171, https://doi.org/10.1016/j.jsg.2017.03.003, 2017a.

Alcalde, J., Bond, C. E., Johnson, G., Ellis, J. F., and Butler, R. W. H.: Impact of seismic image quality on fault interpretation uncertainty, GSA Today, 27, 4-10, https://doi.org/10.1130/GSATG282A.1, 2017b.

Bond, C. E.: Uncertainty in structural interpretation: Lessons to be learnt, J. Struct. Geol., 74, 185-200, https://doi.org/10.1016/j.jsg.2015.03.003, 2015.

Bond, C. E., Gibbs, A. D., Shipton, Z. K., and Jones, S.: What do you think this is? "Conceptual uncertainty" in geoscience interpretation, GSA Today, 17, 4-10, https://doi.org/10.1130/GSAT01711A.1, 2007.

Cabello, P., Falivene, O., López-Blanco, M., Howell, J. A., Arbués, P., and Ramos, E.: An outcrop-based comparison of facies modelling strategies in fan-delta reservoir analogues from the Eocene Sant Llorenç del Munt fan-delta (NE Spain), Petrol. Geosci., 17, 65-90, https://doi.org/10.1144/1354-079309-021, 2011.

Cabello, P., Domínguez, D., Murillo-López, M. H., López-Blanco, M., García-Sellés, D., Cuevas, J. L., Marzo, M., and Arbués, P.: From conventional outcrop datasets and digital outcrop models to flow simulation in the Pont de Montanyana point-bar deposits (Ypresian, Southern Pyrenees), Mar. Petrol. Geol., 94, 19-42, https://doi.org/10.1016/j.marpetgeo.2018.03.040, 2018.

Cabrera, L1., Roca, E., Garcés, M., and de Porta, J.: Estratigrafía y evolución tectonosedimentaria oligocena superior-neógena del sector central del margen catalán (Cadena Costero-Catalana), in: Geología de España, edited by: Vera, J. A., Sociedad Geológica de España and Instituto Geológico y Minero de España, Madrid, Spain, 569-572, 2004.

Fernández, O., Masini, M., Aguilar, R. M., Victoria, M., Briceño, A., and Calderón, P.: Fracture modeling in a complex Carbonate Reservoir: the Lubina-Montanazo field, offshore Spain, 77th EAGE Conference \& Exhibition 2015, Madrid, Spain, 1-4 June 2015, https://doi.org/10.3997/2214-4609.201413529, 2015.

Fomel, S. and Landa, E.: Structural uncertainty of timemigrated seismic images, J. Appl. Geophys., 101, 27-30, https://doi.org/10.1016/j.jappgeo.2013.11.010, 2014.

Granado, P., Urgeles, R., Sàbat, F., Albert-Villanueva, E., Roca, E., Muñoz, J. A., Mazzuca, N., and Gambini, R.: Geodynamical framework and hydrocarbon plays of a salt giant: the NW Mediterranean Basin, Petrol. Geosci., 22, 309-321, https://doi.org/10.1144/petgeo2015-084, 2016.

Hoffman, K. S., Neave, J. W., and Nilsen, E. H.: Model Building with Difficult Faults, SPE Annual Technical Conference and Exhibition, Denver, Colorado, USA, 21-24 September 2008, SPE paper 115324-PP, 2008.

Holden, L., Mostad, P., Nielsen, B. F., Gjerdem J., Townsend, C., and Ottesen, S.: Stochastic Structural Modeling, Math. Geol., 35, 899-914, 2003.

Hollund, K., Mostad, P., Nielsen, B. F., Holden, L., Gjerde, J., Contursi, M. G., McCann, A. J., Townsend, C., and Sverdrup, E.: HAVANA - A Fault Modeling Tool, in: Hydrocarbon Seal Quantification, Norwegian Petroleum Society Conference, Stavanger,
Norway, 16-18 October 2002, NPF Special Publication vol. 11, 1-22, 2002.

Howley, E. and Meyer, R. S.: Developing an integrated structural modelling workflow, First Break, 33, 95-100, 2015.

Jolie, E., Moeck, I., and Faulds, J. E.: Quantitative structuralgeological exploration of fault-controlled geothermal systems - A case study from the Basin-and-Range Province, Nevada (USA), Geothermics, 54, 54-67, https://doi.org/10.1016/j.geothermics.2014.10.003, 2015.

Junbin, H., Lijun, G., and Yong, G.: Side lobes of wavelets impact identification of thin sand bodies, Appl. Geophys., 4, 111-117, https://doi.org/10.1007/s11770-007-0016-9, 2007.

Klimowitz, J., Escalante, S., Hernández, S., and Soto, J. I.: Estructuración tectónica Alpina del margen occidental del Surco de Valencia (Mediterráneo Occidental), Revista de la Sociedad Geológica de España, 31, 83-100, 2018.

Latief, A. I., Ridzuan, A. I., Faehrmann, P. A., MacDonald, A., Nasir, W. A., Rahman, G., and Rahman, M. E.: An Innovative Static Modeling Approach to handle a Complex Giant Mature Field within a Compressed Timeframe; A Case Study of the Baram Oil Field, Offshore Sarawak, East Malaysia, SPE Asia Pacific Oil and Gas Conference and Exhibition, Perth, Australia, 22-24 October 2012, SPE paper 159532-PP, 2012.

Leahy, G. and Skorstad, A.: Uncertainty in subsurface interpretation: a new workflow, First Break, 31, 2013.

MacDonald, A., Zhang, K., Tollefsrud, J. I., Ghanbari, S., and Chelak, R.: Introduction to Reservoir Uncertainty Modeling, CSPG/CSEG/CWLS GeoConvention 2009, Calgary, Alberta, Canada, 4-8 May 2009, AAPG Search and Discovery Article\#90171, 2009.

Maillard, A. and Mauffret, A.: Crustal structure and riftogenesis of the Valencia Trough (north-western Mediterranean Sea), Basin Res., 11, 357-367, 1999.

Manzocchi, T., Carter, J. N., Skorstad, A., Fjellvoll, B., Stephen, K. D., Howell, J. A., Matthews, J. D., Walsh, J. J., Nepveu, M., Bos, Cole, J., Egberts, P., Flint, S., Hern, C., Holden, L., Hovland, H., Jackson, H., Kolbjørnsen, O. , MacDonald, A., Nell, P. A. R., Onyeagoro, K., Strand, J., Syversveen, A. R., Tchistiakov, A., Yang, C., Yielding, G., and Zimmerman, R. W.: Sensitivity of the impact of geological uncertainty on production from faulted and unfaulted shallow-marine oil reservoirs: objectives and methods, Petrol. Geosci., 14, 3-15, 2008.

Neumann, K., Hegstad, B., Bratli, E., and Osmundsen, I.: Uncertainty study on in-place volumes in Statoil, 9th International Geostatistics Congress, Oslo, Norway, 11-15 June 2012.

Pakyuz-Charrier, E., Giraud, J., Ogarko, V., Lindsay, M., and Jessel, M.: Drillhole uncertainty propagation for three-dimensional geological modeling using Monte Carlo, Techyonophysics, 747748, 16-39, https://doi.org/10.1016/j.tecto.2018.09.005, 2018.

Pettan, C. and Strømsvik, J. F.: The Peregrino Challenge: How to Keep Reliable Models While Drilling Eight Wells per Year, Offshore Technology Conference Brasil, Rio de Janeiro, 29-31 October 2013, OTC paper 24522, 2013.

Qu, D., Røe, P., and Tveranger, J.: A method for generating volumetric fault zone grids for pillar gridded reservoir models, Comput. Geosci., 81, 28-37, https://doi.org/10.1016/j.cageo.2015.04.009, 2015. 
Ramos Pinto, V., de S. Abreu, C. E. B., Monteiro, R. C., Rosseto, J., and Leahey, G. M.: Seismic uncertainty estimation in reservoir structural modelling, First Break, 35, 51-54, 2017.

Roca, E.: La evolución geodinámica de la Cuenca Catalano-Balear y áreas adyacentes desde el Mesozoico hasta la actualidad, Acta Geológica Hispánica, 29, 3-25, 1994.

Roca, E., Sans, M., Cabrera, L., and Marzo, M.: Oligocene to Middle Miocene evolution of the central Catalan margin (northwestern Mediterranean), Tectonophysics, 315, 209-233, 1999.

Rodríguez-Morillas, N., Playà, E., Travé, A., and MartínMartín, J. D.: Diagenetic processes in a partially dolomitized carbonate reservoir: Casablanca oil field, Mediterranean Sea, offshore Spain, Geol. Acta, 11, 195-214, https://doi.org/10.1344/105.000001839, 2013.

Rojas, R., Kahunde, S., Peeters, L., Batelaan, O., Feyen, L., and Dassargues, A.: Application of a multimodel approach to account for conceptual model and scenario uncertainties in groundwater modelling, J. Hydrol., 394, 416-435, https://doi.org/10.1016/j.jhydrol.2010.09.016, 2010.

Roma, M., Ferrer, O., Roca, E., Pla, O., Escosa, F. O., and Butillé, M.: Formation and inversion of salt-detached rampsyncline basins. Results from analog modeling and application to the Columbrets Basin (Western Mediterranean), Tectonophysics, 745, 214-228, https://doi.org/10.1016/j.tecto.2018.08.012, 2018.

Røe, P., Georgsen, F., and Abrahamsen, P.: An Uncertainty Model for Fault Shape and Location, Math. Geosci., 46, 957-969, https://doi.org/10.1007/s11004-014-9536-z, 2014.

Schaaf, A. and Bond, C. E.: Quantification of uncertainty in 3-D seismic interpretation: implications for deterministic and stochastic geomodeling and machine learning, Solid Earth, 10, 1049-1061, https://doi.org/10.5194/se-10-1049-2019, 2019.

Seiler, A., Rivenæs, J. C., Aanonsen, S. I., and Evensen, G.: Structural Uncertainty Modelling and Updating by Production Data Integration, SPE/EAGE Reservoir Characterization and Simulation Conference, Abu Dhabi, UAE, 19-21 October 2009, SPE paper 125352, 2009.

Sheriff, R. E.: Vertical and Lateral Seismic Resolution and Attenuation: Part 7. Geophysical Methods, in: Development Geology Reference Manual, edited by: Morton-Thompson, D. and Woods, A. M., AAPG, Tulsa, Oklahoma, USA, 388-398, 1992.
Skjervheim, J.A., van Lanen, X., Hulme, D., Stenerud, V. R., Zachariassen, E., Liu, S., Hove, J., and Evensen, G.: Integrated workflow for consistent model building from depth conversion to flow Simulation - North Sea Field Case, 74th EAGE Conference \& Exhibition incorporating SPE EUROPEC 2012, Copenhagen, Denmark, 4-7 June 2012, EAGE paper D034, 2012.

Stenerud, V. R., Kallekleiv, H., Abrahamsen, P., Dahle, P., Skorstad, A., and Aalmen Viken, M. H.: Added value by fast and robust conditioning of structural surfaces to horizontal wells for real-world reservoirs, SPE Annual Technical Conference and Exhibition, San Antonio, Texas, 8-10 October 2012, SPE paper 159746, 2012.

Suslick, A. B., Schiozer, D., and Rodriguez, M. R.: Uncertainty and Risk Analysis in Petroleum Exploration and Production, Terræ, 6, 30-41, 2009.

Taylor, J.: Introduction to error analysis, the study of uncertainties in physical measurements, University Science Book, Sausalito, California, 348 pp., 1997.

Thore, P., Shtuka, A., Lecour, M., Ait-Ettajer, T., and Cognot, R.: Structural uncertainties: Determination, management, and applications, Geophysics 67, 840-852, 2002.

Wellmann, J. F. and Regenauer-Lieb, K.: Effect of geological quality on uncertainties in geological models and subsurface flow fields, in: Proceedings of the Thirty-Seventh Workshop on Geothermal Reservoir Engineering, Stanford University, Stanford, California, USA, 30 January-1 February 2012, SGP-TR194, 2012.

Wellmann, J. F., Horowitz, F. G., Schill, E., and RegenauerLieb, K.: Towards incorporating uncertainty of structural data in 3D geological inversion, Tectonophysics, 490, 141-151, https://doi.org/10.1016/j.tecto.2010.04.022, 2010. 